\title{
Dichlorodioxomolybdenum(VI) complexes: useful and readily available catalysts in organic synthesis
}

Raquel Hernández-Ruiz

Roberto Sanz*

Área de Química Orgánica, Departamento de Química,

Facultad de Ciencias, Pza. Misael Bañuelos s/n, Universidad de

Burgos, 09001 Burgos, Spain.

rsd@ubu.es

Click here to insert a dedication

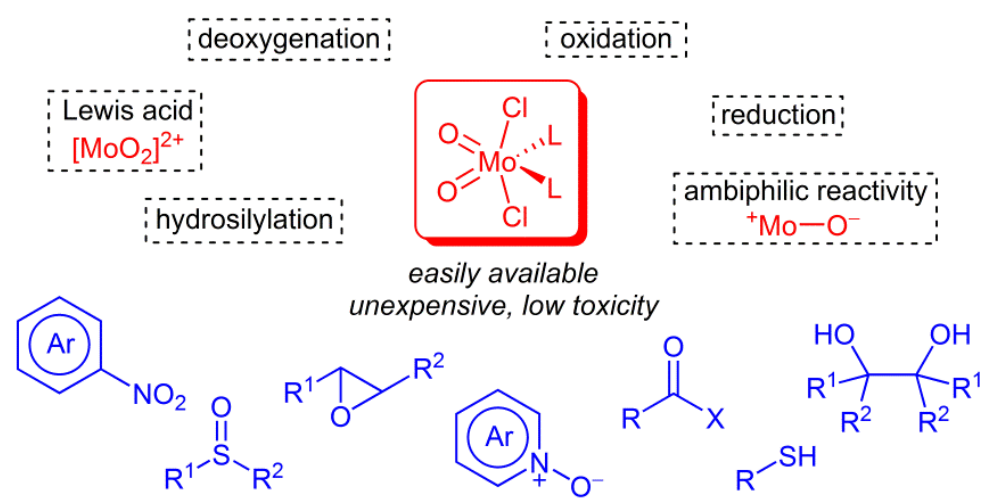

\section{Received:
Accepted:
Published onlin :}

Abstract Molybdenum(VI) dichloride dioxide $\left(\mathrm{MoO}_{2} \mathrm{Cl}_{2}\right)$, and its addition complexes $\left(\mathrm{MoO}_{2} \mathrm{Cl}_{2}(\mathrm{~L})_{n} ; \mathrm{L}=\right.$ neutral ligand), are commercially or easily available and inexpensive transition metal complexes based on a non-noble metal that can be applied as catalysts for various organic transformations. This short review aims to present the most significant breakthroughs in this field.

2 Preparation and Reactivity of $\mathrm{MoO}_{2} \mathrm{Cl}_{2}(\mathrm{~L})_{n}$ Complexes

$2.1 \quad$ Synthesis and Structure

2.2 Reactivity of Dichlorodioxomolybdenum(VI) Complexes

3 Redox Processes Catalyzed by $\mathrm{MoO}_{2} \mathrm{Cl}_{2}(\mathrm{~L})_{n}$ Complexes

3.1 Deoxygenation Reactions Using Phosphorous Compounds

3.2 Deoxygenation and Hydrosilylation Reactions Using Silanes

3.3 Reduction Reactions Using Hydrogen

3.4 Deoxygenation Reactions with Boranes and Thiols

3.5 Reduction Reactions with Glycols

3.6 Oxidation Reactions

4 Ambiphilic Reactivity of $\mathrm{MoO}_{2} \mathrm{Cl}_{2}$

4.1 Amphoteric Lewis Acid-Lewis Base Catalyzed Reactions

4.2 Lewis Acid-Type Catalyzed Reactions

$5 \quad$ Conclusion and Perspective

Key words dioxomolybdenum(VI) complexes, reduction, oxidation, deoxygenation, Lewis acid, nitroaromatics, sulfoxides

\section{Introduction}

Molybdenum is a d-block transition metal, which possesses a rich and versatile redox chemistry (with oxidation states varying from $-\mathrm{I}$ to $+\mathrm{VI}$ ), and has played a key role in the evolution of life. Although not very abundant in Earth's crust, it is an essential component of the active sites and cofactors of several enzymes, referred to as oxotransferases, which catalyze electron transfer and oxygen transfer reactions performed on carbon, nitrogen and sulfur substrates. Examples of this type of molybdoenzymes are DMSO reductase, sulfite oxidase, xanthine oxidase, and nitrate reductase. ${ }^{1}$ As its importance in biological systems illustrates, Mo is much less toxic than most of other transition metals.

Derived from its biological significance, extensive research was performed on molybdenum-mediated or catalyzed reactions. $^{2}$ Many chemical approaches have been directed towards mimicking the structure of the active sites of molybdoenzymes in order to achieve a similar chemical reactivity. Oxomolybdenum complexes have therefore attracted notable attention because monooxo- and dioxomolybdenum units are found in the active site of numerous enzymes.

The chemistry of Mo(VI) is almost monopolized by the oxo ligand, an excellent $\sigma$ - and $\pi$-donor, which is able to stabilize the highest oxidation state of Mo through the formation of a formal double bond between the oxo ligand and the metal. Therefore, $\mathrm{Mo}(\mathrm{VI})$ complexes bearing the $\mathrm{cis}-\mathrm{MoO}_{2}{ }^{2+}$ core are the most common ones and have been extensively used to perform a variety of organic transformations due to their ease of synthesis and chemical attributes. A wide variety of dioxomolybdenum(VI) complexes have been reported varying the type and the denticity of the remaining anionic ligands. Among them, $\mathrm{MoO}_{2} \mathrm{Cl}_{2}$ and its addition compounds $\mathrm{MoO}_{2} \mathrm{Cl}_{2}(\mathrm{~L})_{\mathrm{n}}$, along with $\mathrm{MoO}_{2}$ (acac) 2, are the most explored dioxomolybdenum(VI) complexes as catalysts for organic transformations. Although a brief revision about the synthesis, structure and reactivity of $\mathrm{MoO}_{2} \mathrm{Cl}_{2}(\mathrm{~L})_{\mathrm{n}}$ complexes will be presented, this review will be centered on their applications in organic synthesis. ${ }^{3}$ Our main focus will be to examine those processes that have shown potential as synthetic methods, omitting the ones performed as mere tests for the catalytic activity of new complexes. Given their increasing importance in organic synthesis, this short review will provide a summary of the recent and more significant achievements as well as an assessment of the catalytic potential of dichlorodioxomolybdenum(VI) complexes. 


\section{Preparation and Reactivity of $\mathrm{MoO}_{2} \mathrm{Cl}_{2}(\mathrm{~L})_{n}$ Complexes}

\subsection{Synthesis and Structure}

$\mathrm{MoO}_{2} \mathrm{Cl}_{2}$ is a moisture-sensitive compound with a fluffy powder consistency that should be stored under an inert atmosphere. ${ }^{4}$ Although it is commercially available (Aldrich, ca. $7000 € / \mathrm{mol}$ ), this product has been reported, in some occasions, to give poorer yields than the freshly prepared one..$^{5}$ However, its synthesis requires chlorination of $\mathrm{MoO}_{2}$ at $160{ }^{\circ} \mathrm{C}, 5$ or treatment of Mo with dry $\mathrm{O}_{2}$ and $\mathrm{Cl}_{2}$ at $250-350{ }^{\circ} \mathrm{C} .6$ Gratifyingly, cheaper molybdenum sources such as $\mathrm{MoO}_{3}$ and $\mathrm{Na}_{2} \mathrm{MoO}_{4} \cdot 2 \mathrm{H}_{2} \mathrm{O}$ can be used as starting materials for the efficient preparation of addition compounds of molybdenum(VI) dichloride dioxide $\left[\mathrm{MoO}_{2} \mathrm{Cl}_{2}(\mathrm{~L})_{\mathrm{n}}\right]$, in which the ligands enhance the stability of the complex. In this field, Arnáiz pioneered the synthesis of several $\mathrm{MoO}_{2} \mathrm{Cl}_{2}(\mathrm{~L})_{2}$ complexes (L = DMSO, DMF, HMPA) by reaction of $\mathrm{MoO}_{3}$ with $\mathrm{HCl}(6 \mathrm{M})$ and further addition of the ligand (Scheme 1). ${ }^{7}$ An improvement of this protocol was subsequently described starting from $\mathrm{Na}_{2} \mathrm{MoO}_{4} \cdot 2 \mathrm{H}_{2} \mathrm{O}$ as Mo source based on the fact that diethylether is able to extract $\mathrm{MoO}_{2} \mathrm{Cl}_{2}\left(\mathrm{H}_{2} \mathrm{O}\right)_{2}$ from an aqueous solution of sodium molybdate in concentrated $\mathrm{HCl}$. This ethereal solution is an active catalyst by itself and is also a useful precursor of a variety of $\mathrm{MoO}_{2} \mathrm{Cl}_{2}(\mathrm{~L})_{\mathrm{n}}$ adducts by simple addition of the corresponding ligand and further filtration of the resulting solid complexes, which are obtained in almost quantitative yields in pure form (Scheme 1). ${ }^{8}$ Specifically, we have used $\mathrm{MoO}_{2} \mathrm{Cl}_{2}(\mathrm{DMF})_{2}$ for most of our developed methodologies in this field, because it is a crystalline and benchstable solid, easy to weight, and can be prepared in multigram quantities from $\mathrm{Na}_{2} \mathrm{MoO}_{4} \cdot 2 \mathrm{H}_{2} \mathrm{O}$ in almost quantitative yield. Although other procedures are also known for the synthesis of these complexes, for instance starting from $\mathrm{H}_{2} \mathrm{MoO}_{4}$ or $\mathrm{PbMoO}_{4},{ }^{9}$ none of them has been proved superior to our method. Alternatively, the addition complex $\mathrm{MoO}_{2} \mathrm{Cl}_{2}$ (DME) (DME = dimethoxyethane) can also be prepared from $\mathrm{Na}_{2} \mathrm{MoO}_{4}$ in high yield by its treatment with $\mathrm{Me}_{3} \mathrm{SiCl}$ in $\mathrm{DME}$ at $65{ }^{\circ} \mathrm{C}$ (Scheme 1). ${ }^{10}$ Another methodology to prepare $\mathrm{MoO}_{2} \mathrm{Cl}_{2}(\mathrm{~L})_{\mathrm{n}}$ complexes is based on the displacement of THF with $\mathrm{O}$ - or $\mathrm{N}$-ligands from $\mathrm{MoO}_{2} \mathrm{Cl}_{2}$ (THF) 2 , prepared by dissolving $\mathrm{MoO}_{2} \mathrm{Cl}_{2}$ in THF. ${ }^{11}$ With this strategy, a wide variety of complexes, a selection of which is shown in Scheme 1, has been synthesized by different authors and essayed mainly as catalysts in epoxidation reactions.

Regarding the structure of $\mathrm{MoO}_{2} \mathrm{Cl}_{2}(\mathrm{~L})_{\mathrm{n}}$ complexes, sixcoordinate species with a distorted octahedral arrangement are the most common ones. The two oxo ligands are always positioned cis to each other, being the $\mathrm{Mo}=0$ distances and the $\mathrm{O}=\mathrm{Mo}=\mathrm{O}$ angles about $1.65-1.75 \AA$ and $95-110^{\circ}$, respectively. The bond dissociation energy (BDE) for $\mathrm{M}=0$ bond has been estimated $\sim 100 \mathrm{kcal} / \mathrm{mol}^{12}$ When possible, the less $\pi$-bonding donor ligand is situated trans to $\mathrm{Mo}=0$. In addition, a structural trans influence should be expected for the bond trans to the oxo ligand, leading to longer bonds for the same donor type compared to when it is cis to $\mathrm{Mo}=0$. Therefore, the two anionic chlorides are typically trans to each other leaving the remaining two sites for coordination of neutral ligands in a cis manner. Related to its characterization, the cis- $\mathrm{MoO}_{2}{ }^{2+}$ group is clearly identified by characteristic IR absorptions bands (two-band pattern) around $950-870 \mathrm{~cm}^{-1}$ arising from the symmetric and asymmetric $\mathrm{Mo}=\mathrm{O}$ stretching vibrations. Accordingly, most of the $\mathrm{MoO}_{2} \mathrm{Cl}_{2}(\mathrm{~L})_{2}$ complexes present a cis-oxo, trans-Cl, cis- $\mathrm{L}$ configuration (Scheme 1).

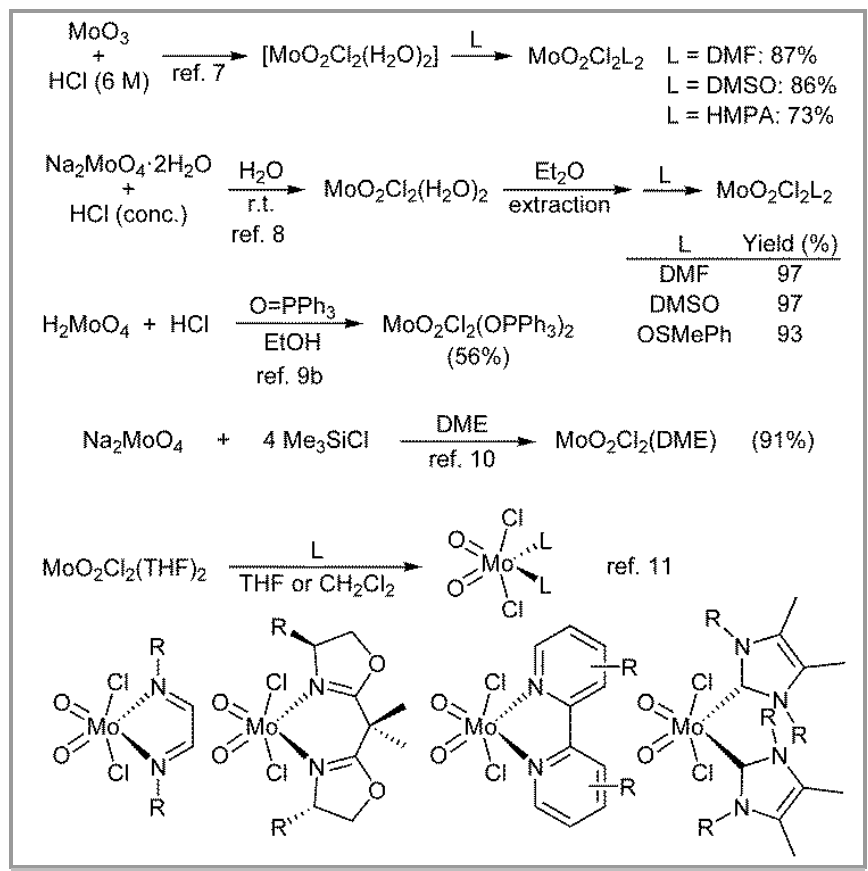

Scheme 1 Synthesis of $\mathrm{MoO}_{2} \mathrm{Cl}_{2}(\mathrm{~L})_{2}$ complexes

\subsection{Reactivity of Dichlorodioxomolybdenum(VI) Complexes}

Oxygen-atom transfer (OAT) reactivity of dioxomolybdenum(VI) complexes is their most distinctive behavior pattern. These reactions typically involve transfer of an oxygen atom to the acceptor coupled with transfer of an electron pair to the donor. In this context, the OAT reaction of $\left[\mathrm{MoO}_{2}\right]^{2+}$ complexes to tertiary phosphines yielding oxomolybdenum(IV) species has been thoroughly studied mainly related to oxotransferase enzymatic activity. ${ }^{13}$ In the case of using sulfoxides as oxygen donors the most accepted proposal, resembling the one suggested for the enzymatic systems, involves the initial oxidation of the phosphine through a direct oxygen transfer from the metal thus leading to a reduction of the Mo(VI) center to a Mo(IV) species. This process could be considered as a nucleophilic attack of the phosphine to an empty $\mathrm{Mo}=0 \pi^{*}$ orbital coupled with a nucleophilic attack of the terminal oxo group on the $\mathrm{P}-\mathrm{C} \sigma^{*}$ orbital. ${ }^{14}$ Release of phosphine oxide from the generated Mo(IV) species would allow a weak coordination of the sulfoxide. Eventually, release of the corresponding sulfide would lead to reoxidation of the metal (Scheme 2). Considering that $\left[\mathrm{MoO}_{2}\right]^{2+}$ complexes possess Lewis acid character, Nieto-Faza and co-workers have recently proposed an alternative mechanistic pathway that not only is energetically more favorable but also avoids spin crossing events associated with the changes in the oxidation state of the metal. ${ }^{15}$ The main difference lies in the first step in which the metal now would behave as a Lewis acid instead of an oxidizing agent, coordinating to the sulfoxide. Then, attack of the phosphine to one of the $\mathrm{Mo}=0$ groups would promote the 
reduction of the metal giving rise to a Mo(IV) species, leading to the strengthening of the interaction between the sulfoxide and the metal. Favorable liberation of the sulfide would lead to a reoxidized complex that keeps the phosphine oxide weakly coordinated. Its final departure would regenerate the initial catalyst (Scheme 2). The rate-determining step in both mechanistic proposals is reduction of Mo(VI) by the phosphine likely due to the partial breakage of the strong $\mathrm{Mo}=0$ bond to form a single $\mathrm{Mo}_{-} \mathrm{OPR}_{3}$ bond, thus correlating the rate of reaction with the phosphine nucleophilicity.

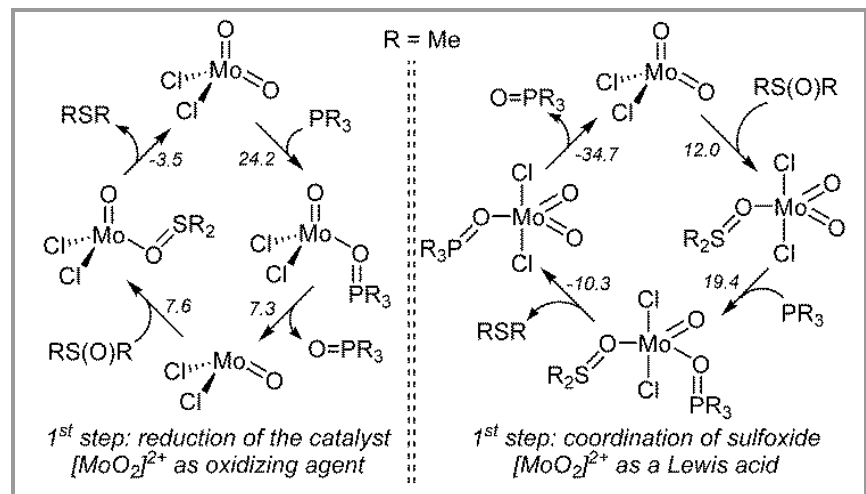

Scheme 2 Different mechanistic pathways for the $\left[\mathrm{MoO}_{2}\right]^{2+}$-catalyzed OAT reaction from $\mathrm{DMSO}$ to $\mathrm{PMe}_{3}$

The reductive activity of dioxomolybdenum(VI) complexes by hydrosilylation, based on Toste's pioneering work on dioxorhenium(V) $\mathrm{ReO}_{2} \mathrm{I}\left(\mathrm{PPh}_{3}\right)_{2}$ as catalyst for the hydrosilylation of carbonyls, ${ }^{16}$ constitutes a different reactivity pattern for these complexes that is described in section 3.2.

As above mentioned, $\left[\mathrm{MoO}_{2}\right]^{2+}$ complexes possess Lewis acid character and, as will be presented in section 4 , they also behave as acid-base combined catalysts due to the amphoteric nature $\left({ }^{+} \mathrm{Mo}-\mathrm{O}^{-}\right)$of the $\mathrm{Mo}=\mathrm{O}$ bond.

\section{Redox Processes Catalyzed by $\mathrm{MoO}_{2} \mathrm{Cl}_{2}(\mathrm{~L})_{2}$ Complexes}

High-valent oxo-molybdenum complexes are useful catalysts for several oxidation and reduction reactions of organic substrates mediated by the Mo(IV/VI) redox system, which is related to the isoelectronic $\mathrm{Re}(\mathrm{V} / \mathrm{VII})$ redox system but with the advantage of the easier availability and lower cost of Mo vs. Re. ${ }^{17}$ Regarding reduction processes, this section will be mainly divided considering the nature of the stoichiometric reducing agent, which is a crucial aspect in the context of sustainable chemistry. Although previously developed, oxidation reactions catalyzed by dioxomolybdenum(VI) complexes possess a more limited synthetic potential.

\subsection{Deoxygenation Reactions Using Phosphorous Compounds}

The deoxygenation of organic compounds is a fundamental reaction extensively used in organic synthesis, requiring in many cases mild conditions, functional group tolerance and selectivity. Dioxomolybdenum(VI) complexes have been employed as catalysts for the deoxygenation of multiple organic substrates. For instance, reduction of sulfoxides to sulfides is an important transformation in the field of asymmetric synthesis because removal of chiral sulfoxide auxiliaries typically requires their first conversion into sulfides. Our group reported in 2004 a useful synthetic methodology, using $\mathrm{MoO}_{2} \mathrm{Cl}_{2}(\mathrm{DMF})_{2}$ as catalyst, for the deoxygenation of sulfoxides to sulfides, employing a stoichiometric amount of triphenylphosphite as oxygenacceptor (Scheme 3).18 The reaction takes place in different solvents such as acetone, THF or MeCN, although the process is faster in the latter. This procedure shows excellent chemoselectivity, as tolerance of other potentially reducible groups such as ester, ketone, halogens, or C-C multiple bonds was demonstrated. High yields were obtained and the byproduct $\mathrm{O}=\mathrm{P}(\mathrm{OPh})_{3}$ could be easily removed $\mathrm{A}$ simplified mechanistic proposal is also shown in Scheme 3 and involves initial reduction of the catalyst by $\mathrm{P}(\mathrm{OPh})_{3}$, which delivers $\mathrm{O}=\mathrm{P}(\mathrm{OPh})_{3}$ and $\mathrm{MoOCl}_{2}(\mathrm{~L})_{2}$. The Mo(IV) species is reoxidized by the sulfoxide releasing the Mo(VI) catalyst and the sulfide.

$$
\mathrm{R}^{1-S_{R^{2}}}+\underset{\substack{\mathrm{P}(\mathrm{OPh})_{3} \\ \text { (1.1 equiv) }}}{\stackrel{\mathrm{MoO}_{2} \mathrm{Cl}_{2}(\mathrm{DMF})_{2}(2 \mathrm{~mol} \%)}{\mathrm{MeCN}, \text { reflux, } 10 \mathrm{~min}-4 \mathrm{~h}}} \mathrm{R}^{1-\mathrm{S}_{\mathrm{R}^{2}}}
$$

Selected examples:

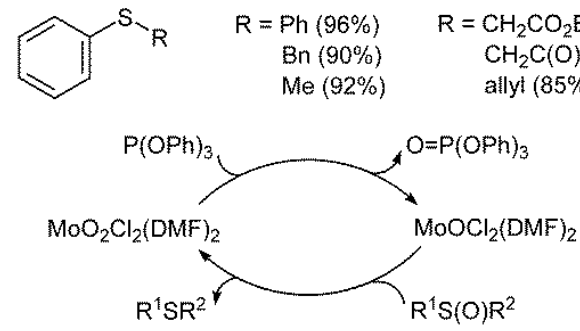

Scheme 3 Deoxygenation of sulfoxides with $\mathrm{P}(\mathrm{OPh})_{3} / \mathrm{MoO}_{2} \mathrm{Cl}_{2}(\mathrm{DMF})_{2}$ (cat.)

The deoxygenation of different heteroaromatic $\mathrm{N}$-oxides, nitrones, and azoxy derivatives, employing $\mathrm{MoO}_{2} \mathrm{Cl}_{2}(\mathrm{DMF})_{2}$ as catalyst and $\mathrm{PPh}_{3}$ as oxygen-acceptor, was also reported by Sanz and co-workers. Again, the reaction proceeds under reflux in different solvents like THF, $\mathrm{MeCN}, \mathrm{CH}_{2} \mathrm{Cl}_{2}$ and toluene (Scheme 4). ${ }^{19}$ Different functional groups are compatible with this method including halogens, alkoxy, as well as free hydroxyl and carboxylic acid. It is also remarkable that a nitro group remains unaltered under reaction conditions. A similar simplified catalytic cycle was proposed, although it should be also considered that Mo(IV) and Mo(VI) species could be in equilibrium with a dinuclear $\mu$-oxomolybdenum(V) $\mathrm{Mo}_{2} \mathrm{O}_{3} \mathrm{Cl}_{4}$ (DMF) ${ }_{4}$ (Scheme 4). ${ }^{20}$ In any case, supposedly a wide variety of oxomolybdenum chlorocomplexes may be active catalysts in these oxo-transfer processes. 


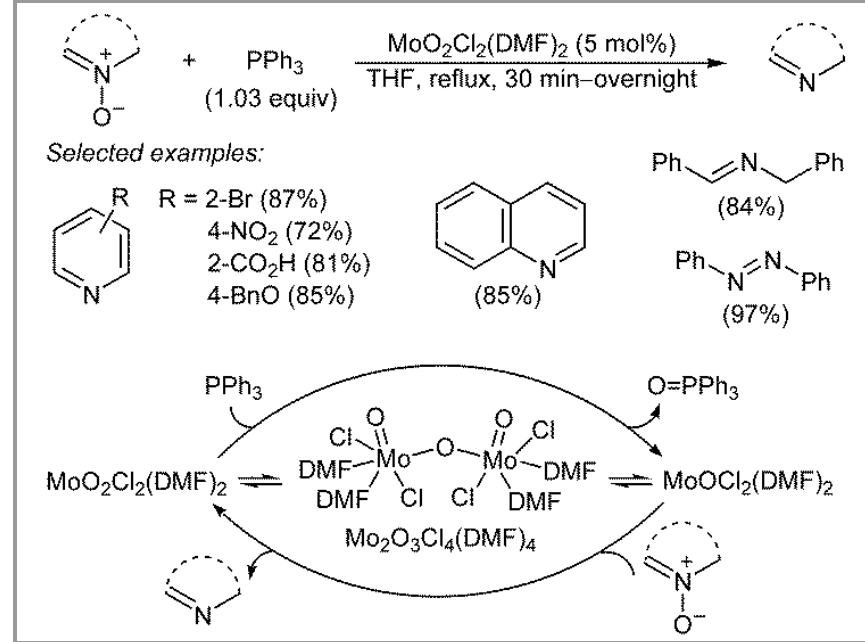

Scheme 4 Deoxygenation of $\mathrm{N}$-oxides with $\mathrm{PPh}_{3} / \mathrm{MoO}_{2} \mathrm{Cl}_{2}(\mathrm{DMF})_{2}$ (cat.)

The Cadogan-Sundberg synthesis of indoles and carbazoles involving reductive cyclization of $o$-nitrostyrenes and $o$ nitrobiphenyls respectively, with trivalent phosphorous reagents is a well-recognized route to synthesize these relevant nitrogenated heterocycles. ${ }^{21}$ As the general conditions involve the use of an excess of $\mathrm{P}(\mathrm{OEt})_{3}$ at reflux, $\mathrm{N}$-ethoxy and $\mathrm{N}$-ethyl derivatives are usually formed in these reactions as side products. ${ }^{22}$ This problem could be avoided by using $\mathrm{PPh}_{3}$ as deoxygenating agent because the corresponding $\mathrm{O}=\mathrm{PPh}_{3}$ is nonelectrophilic. However, the use of $\mathrm{PPh}_{3}$ requires harsh conditions $\left(180{ }^{\circ} \mathrm{C}\right)$ and highly toxic $o$-dichlorobenzene as solvent. ${ }^{23}$ In this field, our research group has developed the Mo-catalyzed Cadogan reductive cyclization of nitroaromatics by treatment of nitrobiphenyls and nitrostyrenes with $\mathrm{PPh}_{3}$ under reflux in toluene catalyzed by $\mathrm{MoO}_{2} \mathrm{Cl}_{2}(\mathrm{DMF})_{2}$ (Scheme 5). ${ }^{24} \mathrm{~A}$ variety of functionalized carbazole and indole derivatives could be obtained in good yields. Moreover, a one-pot procedure for accessing 2-acylindoles and indole 2-carboxylates from 2 nitrobenzaldehydes has been also developed, in which an initial Wittig reaction is followed by reductive cyclization (Scheme 5).

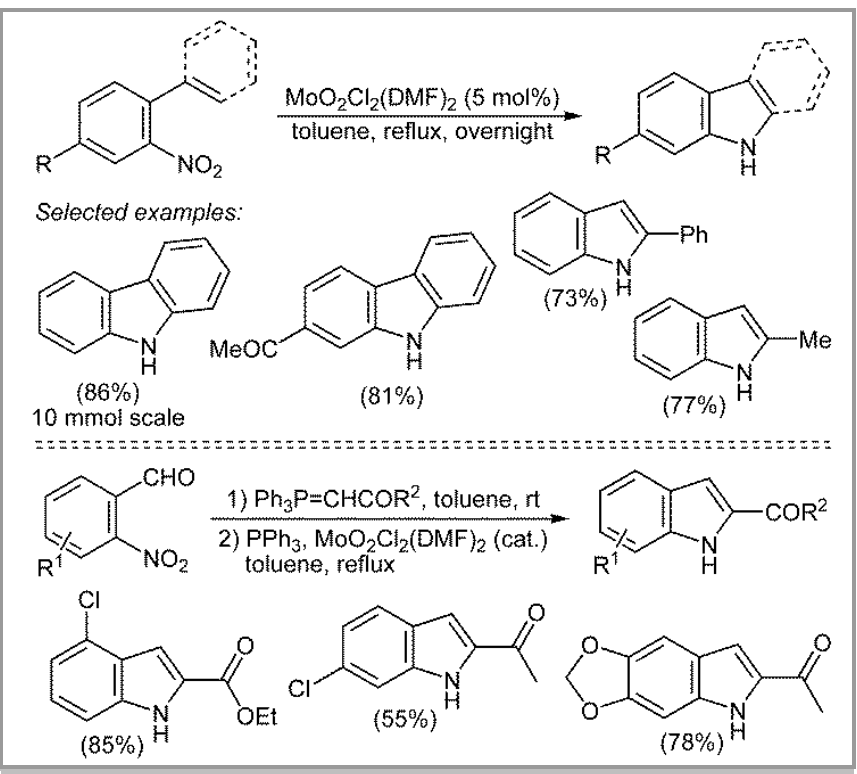

Scheme 5 Mo-catalyzed Cadogan synthesis of carbazoles and indoles
Interestingly, this methodology has been applied by other authors for the preparation of different nitrogenated heterocycles, including 3-aryl-2-trifluoromethyl and 3-aryl-2ethoxycarbonyl indoles in almost quantitative yields, ${ }^{25}$ bromo5,6-dimethoxyindole building blocks, ${ }^{26}$ and pyrroles from the reductive cyclization of nitrodienes (Scheme 6). ${ }^{27}$ Although moderate yields of pyrroles were obtained, this involves a considerable improvement with respect to the non-catalyzed reaction, which leads to very poor yields $(12-14 \%)$ with both $\mathrm{P}(\mathrm{OEt})_{3}$ and $\mathrm{PPh}_{3}$. Beifuss and co-workers have also extended the use of our catalytic system to the reductive cyclization of other nitroaromatics such as allyl $o$-nitroaryl (thio)ethers and $o$ nitrobenzylidene amines, which leads to 3,4-dihydro- $2 H-1,4$ benzoxazines or benzothiazines and 2-aryl- $2 \mathrm{H}$-indazoles, respectively (Scheme 6). ${ }^{28}$

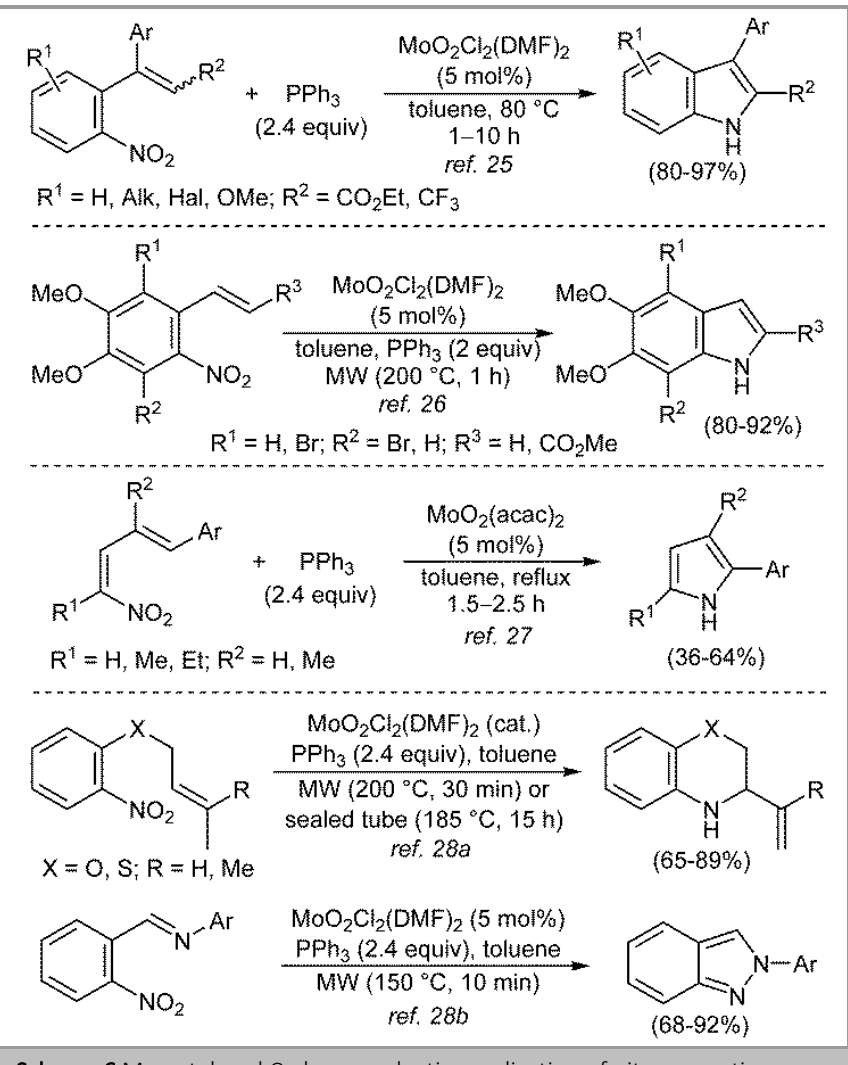

Scheme 6 Mo-catalyzed Cadogan reductive cyclization of nitroaromatics

Again, these authors found that the non-catalyzed reactions with $\mathrm{P}(\mathrm{OEt})_{3}$ take place with lower yields and selectivity. Interestingly, they also described the use of microwave heating as an alternative to the conventional refluxing conditions, shortening dramatically the reaction time to $10-30 \mathrm{~min}$ (Scheme 6).

Regarding the mechanism of these Mo-catalyzed reductive cyclization reactions of nitroaromatics, we proposed that both the oxomolybdenum(IV) complex, resulting from initial reduction of the dioxomolybdenum(VI) catalyst, as well as the likely dinuclear $\mu$-oxomolybdenum(V) generated from comproportionation of molybdenum(IV) and (VI) species, could deoxygenate the starting nitroaromatic to the corresponding nitroso derivative (Scheme 7). ${ }^{24}$ From this intermediate two possible pathways could be postulated. Further deoxygenation could be achieved with the second equivalent of $\mathrm{PPh}_{3}$ to a 
singlet nitrene, which could undergo a formal $\mathrm{C}-\mathrm{H}$ insertion to afford the corresponding nitrogenated heterocycle. This second reduction step could also take place in the absence of the catalyst. Alternatively, the nitroso intermediate could evolve through a $6 \pi$-electron 5-atom electrocyclization leading to a nitronate that would require a subsequent $1,5-\mathrm{H}$ shift prior to isomerisation to a $\mathrm{N}$-hydroxy derivative. Its final reduction with the second equivalent of $\mathrm{PPh}_{3}$ would allow the formation of the $N$-heterocycle. Both mechanistic proposals have been suggested and supported by different authors and, therefore, the activation barriers for both types of processes could be different depending on the substrate and reaction conditions. ${ }^{29}$

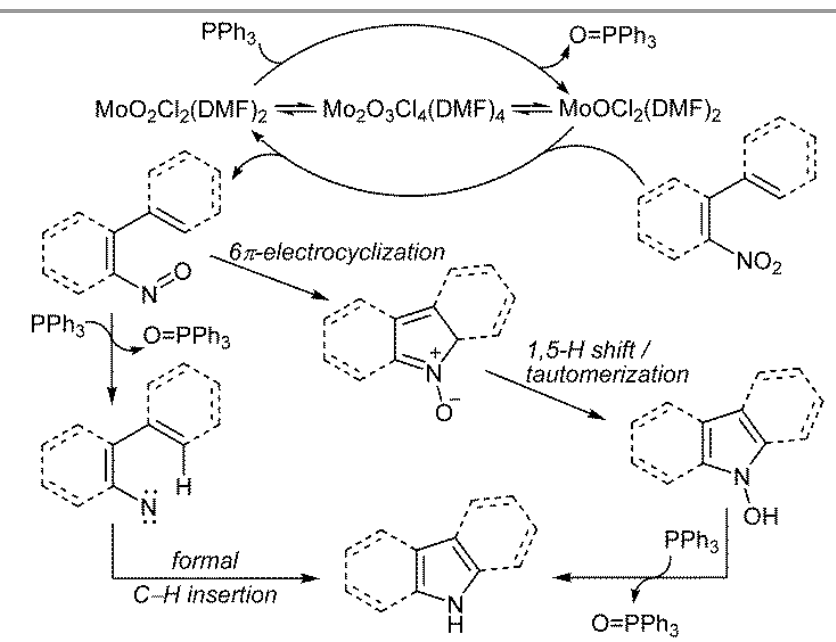

Scheme 7 Mechanistic proposal for the Mo-catalyzed reductive cyclization of nitroaromatics

On the other hand, the deoxygenation of epoxides, the reverse reaction of the epoxidation of olefins, is a useful although underexplored strategy for the stereoselective synthesis of alkenes. Most of the reported procedures are catalyzed by oxorhenium complexes, ${ }^{30}$ and only a particular example had been reported for the deoxygenation of styrene oxide in very low yield, catalyzed by $\mathrm{MoO}_{2} \mathrm{Cl}_{2}$ (DME). ${ }^{31}$ However, in 2016 Asako, Takai and co-workers reported the stereospecific deoxygenation of epoxides using $\mathrm{MoO}_{2} \mathrm{Cl}_{2}$ as catalyst and phosphines as reducing agents in toluene. ${ }^{32}$ Interestingly, the stereoselectivity can be controlled by the nature of the phosphine and so, reactions with 1,2bis(diphenylphosphino)ethane (dppe) take place with retention of the stereochemistry of the alkene whereas the use of $\mathrm{PPh}_{3}$ as reductant leads to inversion (Scheme 8). In relation with the chemoselectivity of the process, while functional groups such as ester, ketone, nitrile, alkynes, or alcohols do not affect the stereoselectivity, other groups like carboxylic acid, aldehyde and phenol have a negative influence. Good yields were obtained for di- and trisubstitued epoxides using dppe. However, with $\mathrm{PPh}_{3}$ the scope was clearly more limited and only selected cis-disubstituted epoxides afforded good results. In their mechanistic proposal, the authors postulated that the reduced Mo(IV) species could react with the epoxide affording a molybdenum diolate (molybdena-2,5-dioxolane) intermediate. The stereoretentive olefin generation using dppe (0.6 equiv) suggested an intermediate in which the dppe monoxide could also act as oxygen acceptor. Alternatively, intermolecular attack of $\mathrm{PPh}_{3}$ to the diolate complex would give rise to an oxaphosphetane intermediate that would subsequently release the olefin with inversion of the stereochemistry (Scheme 8).

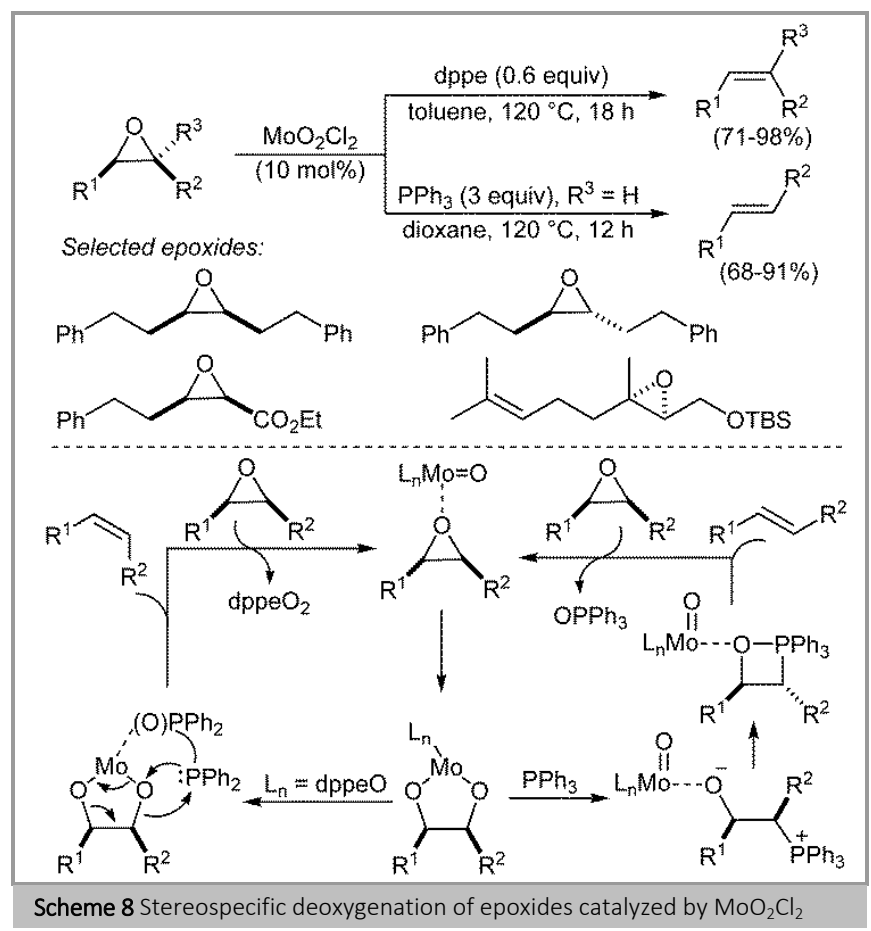

3.2

\section{Deoxygenation and Hydrosilylation Reactions Using Silanes}

Following the pioneering work by Toste and co-workers on the hydrosilylation of aldehydes and ketones with $\mathrm{Me}_{2} \mathrm{PhSiH}$ under catalysis of a dioxorhenium(V) complex,16 Royo and coworkers described this type of reactivity, which involves the conversion of an oxidizing $\mathrm{M}=0$ complex to a potentially reducing $\mathrm{H}-\mathrm{M}-\mathrm{OSiR}{ }_{3}$ complex, but using dioxomolybdenum(VI) complexes. They reported that $\mathrm{MoO}_{2} \mathrm{Cl}_{2}$ catalyzes the hydrosilylation of carbonyls with $\mathrm{Me}_{2} \mathrm{PhSiH}$ giving rise to the corresponding dimethylphenylsilyl ethers (Scheme 9). ${ }^{33}$ Reactions were initially carried out in $\mathrm{CH}_{2} \mathrm{Cl}_{2}$ with variable yields but, gratifyingly, changing the solvent to MeCN afforded the corresponding silylated ethers in higher yields at room temperature for aldehydes and at reflux for ketones. Interestingly, among Mo complexes $\mathrm{MoO}_{2} \mathrm{Cl}_{2}$ was found to be the most active catalyst as replacement of $\mathrm{Cl}$ by other anionic $\mathrm{C}-, \mathrm{O}-$, or S-ligands decreased its catalytic activity thus requiring higher temperatures and longer reaction times. The same authors have also developed an analogous hydrosilylation of imines confirming the ability of $\mathrm{MoO}_{2} \mathrm{Cl}_{2}$ to efficiently catalyze this type of reactions. Chemoselective reduction of imines was achieved using $\mathrm{PhSiH}_{3}$ in refluxing THF (Scheme 9). ${ }^{34}$ Moreover, inexpensive and non-toxic polymethylhydrosiloxane (PMHS) was also proved effective as reducing agent. Later on, Smith and co-workers developed the direct reductive amination of electron-deficient as well as electron-rich benzaldehydes with a variety of primary amines, $\mathrm{PhSiH}_{3}$ as reducing agent, and catalytic $\mathrm{MoO}_{2} \mathrm{Cl}_{2}$, using different solvents such as $\mathrm{MeOH}, \mathrm{EtOH}$, dioxane and $\mathrm{CH}_{2} \mathrm{Cl}_{2}$-THF. They also found that the presence of water is well-tolerated (Scheme 9). ${ }^{35}$ 


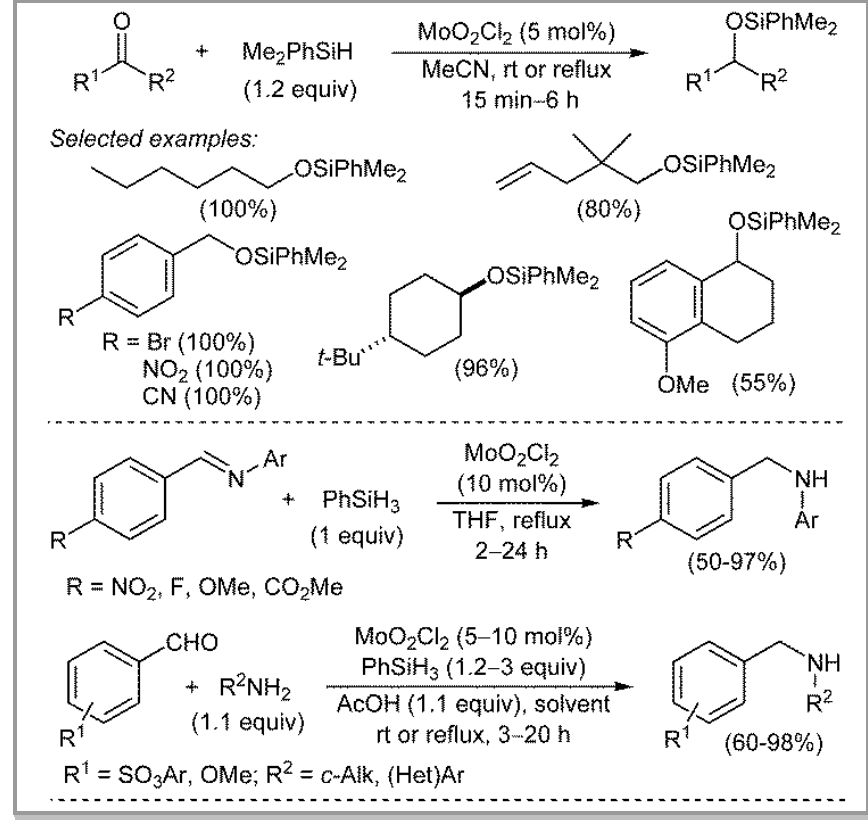

Scheme $9 \mathrm{MoO}_{2} \mathrm{Cl}_{2}$-catalyzed hydrosilylation of carbonyls and imines.

Fernandes and Romão have described similar hydrosilylation reactions to reduce esters ${ }^{36}$ and amides. ${ }^{37}$ For the reduction of both functional groups, $\mathrm{PhSiH}_{3}$ was used in refluxing toluene and in the presence of catalytic amounts of $\mathrm{MoO}_{2} \mathrm{Cl}_{2}$. In addition, PMHS resulted to be also a suitable replacement for $\mathrm{PhSiH}_{3}$. Both aliphatic and aromatic esters were efficiently reduced to the corresponding alcohols in good yields (Scheme 10). On the other hand, secondary, as well as hindered tertiary amides could be reduced in moderate to good yields to the corresponding amines although a higher catalyst loading was required (Scheme 10). Experiments with $\mathrm{PhMe}_{2} \mathrm{SiD}$ suggested a prior reduction of the amide to an imine intermediate that is further reduced to the corresponding amine.

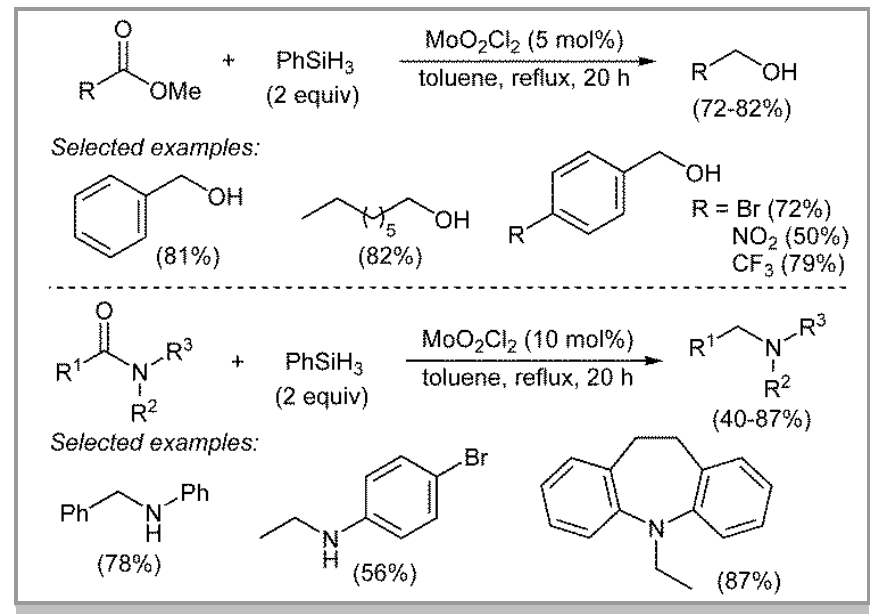

Scheme 10 Mo-catalyzed hydrosilylation of esters and amides with $\mathrm{PhSiH}_{3}$

Fernandes and Romão have also described the deoxygenation of sulfoxides and picoline $\mathrm{N}$-oxides with $\mathrm{PhSiH}_{3}$ as oxygen acceptor and $\mathrm{MoO}_{2} \mathrm{Cl}_{2}$ as catalyst (Scheme 11). ${ }^{38} \mathrm{An}$ alternative greener protocol was also developed in water or $\mathrm{MeOH}$ using PMHS and easily available $\mathrm{MoO}_{2} \mathrm{Cl}_{2}\left(\mathrm{H}_{2} \mathrm{O}\right)_{2}$ as catalyst (see Scheme 1). High yields were obtained for the reduction of a selection of functionalized sulfoxides and 3- and 4-picoline $\mathrm{N}$-oxides.

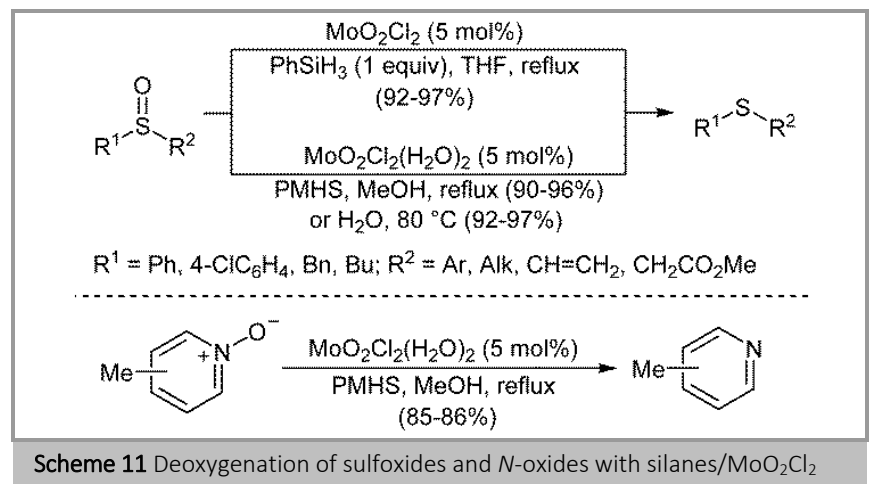

In 2015, Fernandes described the selective deoxygenation of aryl ketones to the corresponding olefins with the $\mathrm{PhSiH}_{3} / \mathrm{MoO}_{2} \mathrm{Cl}_{2}\left(\mathrm{H}_{2} \mathrm{O}\right)_{2}$ system that allows the obtention of alkenes in excellent yields without the need of inert atmosphere or dried solvents (Scheme 12). ${ }^{39}$ However, under these conditions non-aryl ketones such as cyclohexanone or $\beta$ tetralone were not efficiently deoxygenated. The Mo-complex was also able to catalyze the dehydration of benzylic alcohols, suggesting that an initial hydrosilylation of the ketone is followed by a subsequent dehydration.

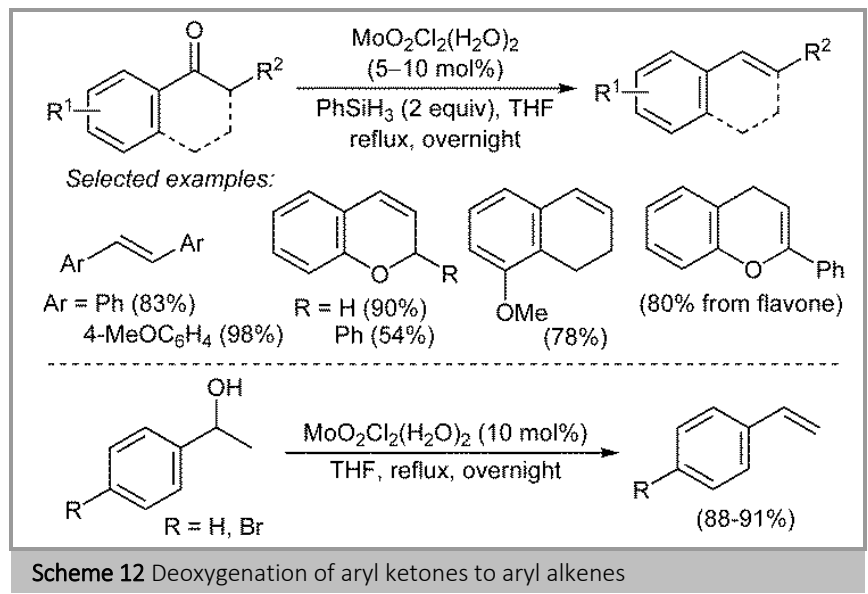

As described above, $\mathrm{MoO}_{2} \mathrm{Cl}_{2}$ is able to effectively catalyze the hydrosilylation reaction of carbonyls and other functional groups. DFT calculations carried out independently by Calhorda and Strassner shed light about the reductive activity of this high-valent oxomolybdenum(VI) complex. ${ }^{40}$ The most favourable pathway, both thermodynamically and kinetically, for the $\mathrm{Si}-\mathrm{H}$ activation resulted a [2+2] addition to the $\mathrm{Mo}=0$ bond, which leads to a hydride species $\mathrm{Mo}(0) \mathrm{H}\left(\mathrm{OSiR}_{3}\right) \mathrm{Cl}_{2}$. In the absence of the carbonyl group a new complex $\mathrm{Mo}(\mathrm{O})\left(\mathrm{OSiR}_{3}\right)_{2} \mathrm{Cl}_{2}$ could be isolated supporting the [2+2] addition path. After weak coordination of the carbonyl to the intermediate Mo-hydride complex, both authors support the stepwise classical mechanism involving the transfer of the $\mathrm{H}$ atom to the carbonyl $\mathrm{C}$ atom and subsequent migration of the silyl group to the alkoxide, to explain the silyl ether formation. However, when $\mathrm{MeCN}$ is used as solvent Calhorda postulated that an alternative radical path, with an energy requirement similar to the classical pathway, could be operative to account for the experimental 
results, as radical scavengers inhibit or slow down the reaction to a great extent (Scheme 13). ${ }^{40 a}$ More recently, Wei and coworkers have proposed that an ionic outer-sphere mechanistic pathway is the most favourable for this Mo-catalyzed hydrosilylation. The key step would be a nucleophilic attack of the $\mathrm{O}$ atom, from $\mathrm{C}=0$, to $\mathrm{Si}$ in a $\eta^{1}$-silane molybdenum adduct with a subsequent heterolytic cleavage of the $\mathrm{Si}-\mathrm{H}$ bond. This process features a novel $\mathrm{S}_{\mathrm{N}} 2 @ S i$ transition state, leading to an anionic Mo hydride paired with a silylcarbenium ion $\left(\left[\mathrm{MoO}_{2} \mathrm{Cl}_{2} \mathrm{H}\right]^{-}\left[\mathrm{SiR}_{3}\left(\mathrm{OCR}^{\prime} \mathrm{R}^{\prime \prime}\right]^{+}\right)\right.$. A final abstraction of the hydride from $\mathrm{Mo}-\mathrm{H}$ by the silylcarbenium would yield the silyl ether (Scheme 13). ${ }^{40 c}$ A closely related ionic pathway has been also proposed for the hydrosilylation of imines, without the need for coordination of the organic substrate to the metal and subsequent insertion into the Mo-H bond. ${ }^{40 \mathrm{~d}}$

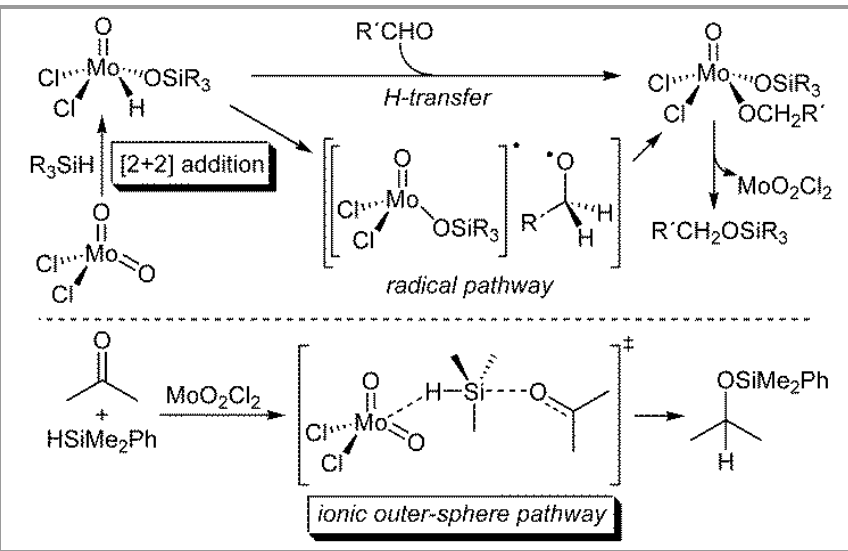

Scheme 13 DFT-based mechanistic proposals for the Mo-catalyzed hydrosilylation reaction

\subsection{Reduction Reactions Using Hydrogen}

Royo and co-workers reported that high-valent oxomolybdenum(VI) complexes, as well as $\operatorname{Re}(\mathrm{VII})$ and $\mathrm{Re}(\mathrm{V})$ ones, are able to activate hydrogen and catalyze some reduction reactions. In such a way, the hydrogenation of alkynes to alkenes takes place under $40 \mathrm{~atm}$ of $\mathrm{H}_{2}$ pressure. However, the authors only reported high conversion for 1-hexyne, whereas phenylacetylene or internal alkynes proceeded with low conversions (Scheme 14). On the other hand, dibutyl and methyl phenyl sulfoxide were efficiently deoxygenated to the corresponding sulfides at $120{ }^{\circ} \mathrm{C}$ under 50 atm of $\mathrm{H}_{2}$ pressure (Scheme 14). ${ }^{41}$ In addition, selected nitroaromatics and pyridine $N$-oxides could be also reduced with the $\mathrm{H}_{2} / \mathrm{MoO}_{2} \mathrm{Cl}_{2}$ catalytic system. This method is highly chemoselective as other reducible groups such as halogens, ketone, aldehyde, cyano, vinyl, or amide are well-tolerated (Scheme 14).42 DFT calculations supported that the mechanism for $\mathrm{H}_{2}$ activation starts in an analogous way to the activation of $\mathrm{Si}-\mathrm{H}$ in silanes, i.e with a $[2+2]$ addition of the $\mathrm{H}-\mathrm{H}$ bond to the $\mathrm{Mo}=\mathrm{O}$ moiety, followed by hydride migration to the oxygen atom leading to the water complex $\mathrm{MoO}\left(\mathrm{H}_{2} \mathrm{O}\right) \mathrm{Cl}_{2}$. However, no pathway was encountered for water elimination from this intermediate and so, the first step could probably be the formation of the addition compounds of $\mathrm{MoO}_{2} \mathrm{Cl}_{2}$ with sulfoxides or $N$-oxides, $\mathrm{MoO}_{2} \mathrm{Cl}_{2} \mathrm{~L} 2$ ( $\mathrm{L}=\mathrm{R}_{2} \mathrm{SO}$ or Py-NO), which may transform into the catalytically active Mo(IV) species in the same way that deoxygenation of sulfoxides or $\mathrm{N}$-oxides with $\mathrm{P}(\mathrm{III})$ reagents takes place (Scheme 14).

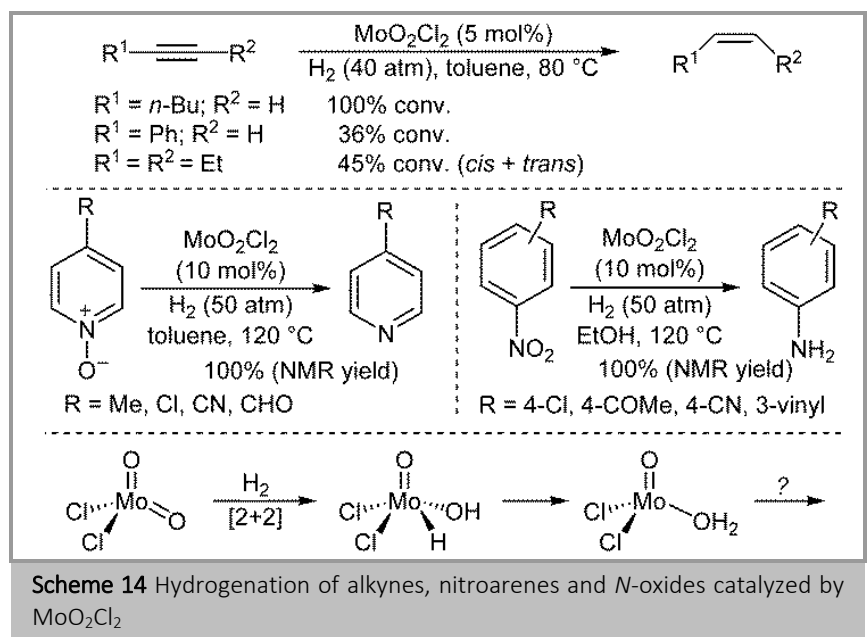

\subsection{Deoxygenation Reactions with Boranes and Thiols}

$\mathrm{B}-\mathrm{H}$ bonds have also been used to deoxygenate sulfoxides catalyzed by $\mathrm{MoO}_{2} \mathrm{Cl}_{2}$ or $\mathrm{MoO}_{2} \mathrm{Cl}_{2}\left(\mathrm{H}_{2} \mathrm{O}\right)_{2}$. Catecholborane (HBcat) or $\mathrm{BH}_{3} \cdot \mathrm{THF}$ can be used as oxygen acceptors yielding the corresponding sulfides in high yields (Scheme 15). ${ }^{43}$ In the mechanistic proposal, also supported by DFT calculations, ${ }^{44}$ the in situ generated $\mathrm{MoO}_{2} \mathrm{Cl}_{2}\left(\mathrm{R}_{2} \mathrm{SO}\right)_{2}$ could activate the $\mathrm{B}-\mathrm{H}$ bond in an analogous way to the $\mathrm{Si}-\mathrm{H}$ bond in silanes. Through the coordination of one oxo ligand to the empty orbital of the boron an intermediate hydride complex could be generated, which upon HOBcat elimination, would lead to the reduced Mo(IV) species that deoxygenates the sulfoxide releasing the catalyst (Scheme 15). An alternative mechanism for the non-explored hydroboration of carbonyls, supported by theoretical calculations, would involve an ionic pathway in which the carbonyl acts as a nucleophile attacking the Mo-borane adduct. This would result into the heterolytic cleavage of the B-H bond and prompt the formation of a borylated carbonyl. The transfer of the hydride attached to the Mo center would yield the boryl ether product. $44 \mathrm{~b}$

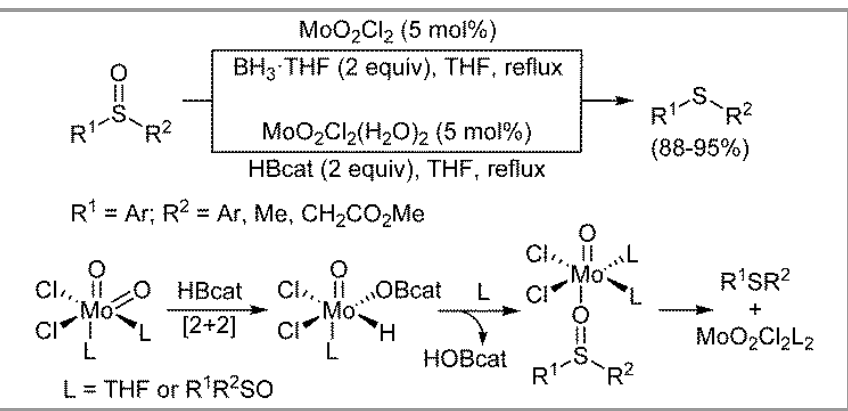

Scheme $15 \mathrm{MoO}_{2} \mathrm{Cl}_{2}$-catalyzed deoxygenation of sulfoxides with boranes

Our research group has developed a different method for the Mo-catalyzed sulfoxide deoxygenation that employs mercaptopropyl-functionalized silica gel (MPS) as reducing agent and microwave irradiation (Scheme 16). ${ }^{45}$ Several dioxomolybdenum(VI) complexes proved to be efficient 
catalysts although $\mathrm{MoO}_{2} \mathrm{Cl}_{2}(\mathrm{DMF})_{2}$ was selected in view of its easy preparation and high stability. Very similar results were obtained using both commercially available Quadrasil ${ }^{\mathrm{TM}}$ MP and synthesized MPS ( $1.2 \mathrm{mmol} \mathrm{g}^{-1}$ loading). A wide range of sulfoxides bearing several potentially reducible functional groups resulted to be suitable substrates showing the remarkable chemoselectivity of this protocol. In this case, a thiolate complex is proposed as intermediate, which would undergo reductive elimination of an heterogeneous sulfenic acid derivative yielding the Mo(IV) species responsible for the sulfoxide deoxygenation. However, this proposal has not been supported by theoretical calculations.

$$
\begin{gathered}
\text { Selected examples: } \\
\text { (1.1 equiv) }
\end{gathered}
$$

Scheme 16 Mo-catalyzed deoxygenation of sulfoxides with mercaptopropylfunctionalized silica gel (MPS)

\subsection{Reduction Reactions with Glycols}

In 2012, Sanz and co-workers reported the use of pinacol as a new environmentally benign oxygen acceptor for the reduction of sulfoxides and nitroaromatics assisted by $\mathrm{MoO}_{2} \mathrm{Cl}_{2}(\mathrm{DMF})_{2}{ }^{46}$ This pioneering work in the field was based on a report from Baker, Thorn and co-workers in which oxovanadium(V) dipicolinate complexes were shown to be able to catalyze the aerobic oxidative $\mathrm{C}-\mathrm{C}$ cleavage of pinacol, whereas under anaerobic conditions a vanadium(III) $\mu$-oxo dimer was generated. ${ }^{47} \mathrm{~A}$ wide range of sulfoxides including substrates bearing challenging functional groups, such as $\mathrm{C}=\mathrm{C}$, $\mathrm{C}=\mathrm{O}, \mathrm{C} \equiv \mathrm{N}, \mathrm{CO}_{2} \mathrm{H}$ and $\mathrm{NO}_{2}$, were selectively and efficiently deoxygenated (Scheme 17). The method, which can be applied to multigram scale $(50 \mathrm{mmol})$, can be carried out under conventional heating in a solvent-free procedure or under microwave irradiation that shortens the reaction time from hours (2-4) to minutes (5-10). We proposed a catalytic cycle in which the first step would be the formation of the pinacolate complex $\mathrm{Mo}$ (pinacolate) $\mathrm{Cl}_{2}(\mathrm{DMF})_{2}$ by condensation of water from one of the oxo ligands and pinacol. Oxidation of the pinacolate ligand by the Mo(VI) center would yield the oxomolydenum(IV) species $\mathrm{MoOCl}_{2}(\mathrm{DMF})_{2}\left(\mathrm{Me}_{2} \mathrm{CO}\right)$ from which the weakly coordinated acetone molecule would be displaced by the sulfoxide. The unstable complex thus generated, $\mathrm{MoOCl}_{2}(\mathrm{DMF})_{2}\left(\mathrm{R}^{1} \mathrm{R}^{2} \mathrm{SO}\right)$, would easily evolve through reoxidation of the metal center releasing the sulfide and the catalyst (Scheme 17). This proposal was partially proved by the fact that the dinuclear oxomolybdenum(V) complex $\mathrm{Mo}_{2} \mathrm{O}_{3} \mathrm{Cl}_{4}(\mathrm{DMF})_{4}$, which also resulted to be catalytically active, could be isolated from the reaction of $\mathrm{MoO}_{2} \mathrm{Cl}_{2}(\mathrm{DMF})_{2}$ with a slight excess of pinacol. This supports the formation of an oxomolybdenum(IV) species that comproportionates with the parent dioxomolybdenum(VI) complex. Therefore, pinacol behaves as an environmentally friendly oxo-acceptor, being acetone and water the only byproducts.

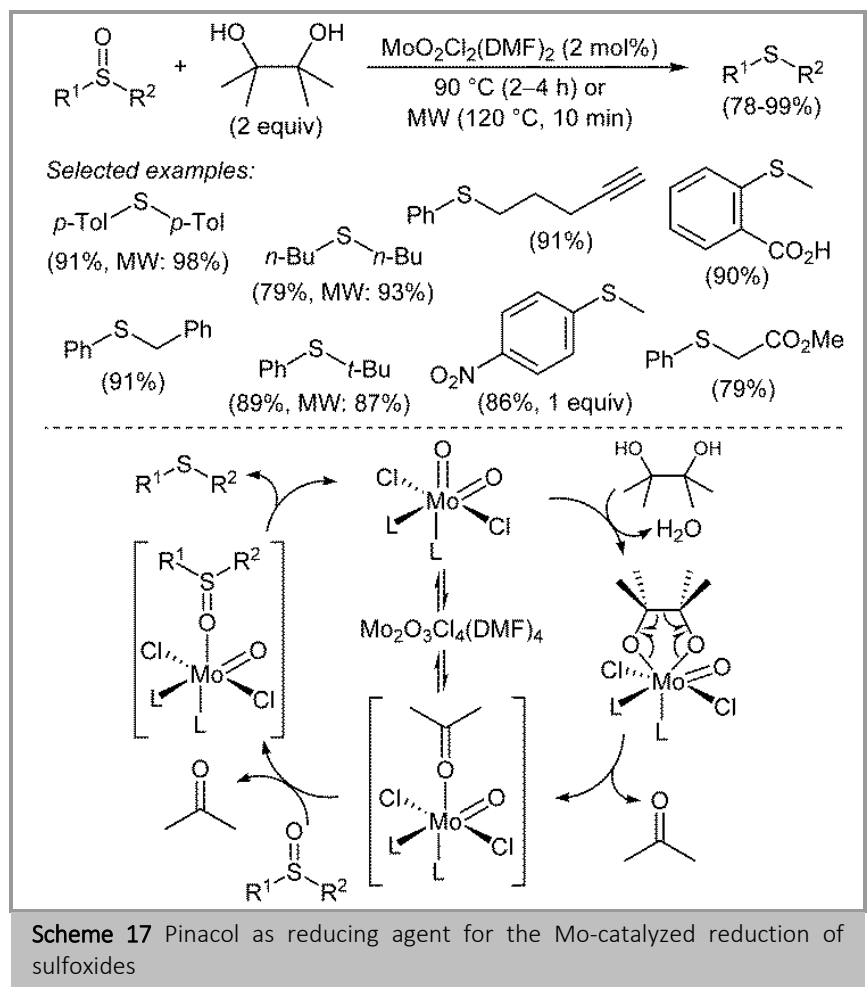

In analogous way, a wide range of nitroaromatic compounds could be selectively and efficiently reduced to the corresponding anilines, including substrates with potentially reducible functional groups such as $\mathrm{C}=\mathrm{C}$, ester, amide, carbonyl, halogen, cyano, and hydroxyl (Scheme 18). Nitroarenes required a slightly higher amount of catalyst compared to the sulfoxides and the presence of a solvent. This methodology could also be applied to multigram scale, and microwave irradiation could be used as an alternative to conventional heating, thus shortening reaction times from hours to minutes. Interestingly, starting from 2-nitrobiphenyl selective reductions can be performed to carbazole or 2-aminobiphenyl depending on the oxo-acceptor employed (Scheme 18). 


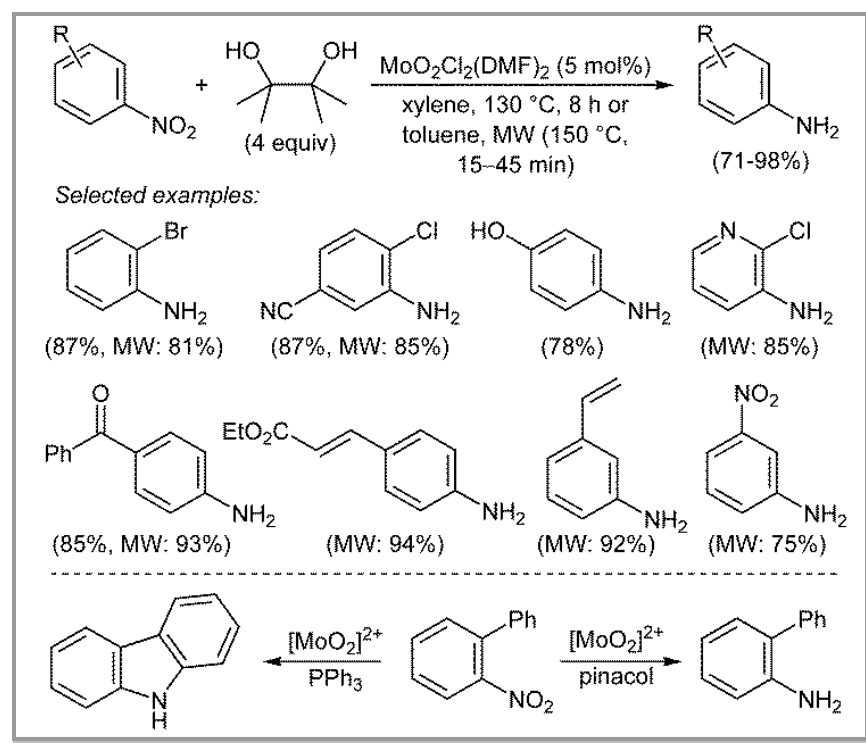

Scheme 18 Pinacol as reducing agent for the Mo-catalyzed reduction of nitroaromatics

In this field, our group has also developed the reduction of sulfoxides, catalyzed by $\mathrm{MoO}_{2} \mathrm{Cl}_{2}(\mathrm{DMF})_{2}$, using glycerol both as solvent and reducing agent. The method presents excellent chemoselectivity, similar to that observed with pinacol, for functionalized diaryl and alkyl aryl sulfoxides (Scheme 19). ${ }^{48}$ Reactions were performed under both conventional heating and microwave irradiation, and the catalyst could be reused up to five times without a significant change of its activity. In addition, this procedure can be applied to the multigram preparation of sulfides (25 mmol scale). Looking for the valorization of glycerol, a by-product from the biodiesel production, the fact that crude glycerin (with $\sim 5-8 \%$ of glycerol content) could also be employed instead of refined glycerol resulted highly interesting. It was checked that 1 equiv of glycerol was able to reduce up to 6 equiv of sulfoxide suggesting that glycerol was being transformed into $\mathrm{CO}_{2}$ and formic acid. In addition, a variety of possible products generated by the oxidation of glycerol, such as dihydroxyacetone, tartronic acid, glycolaldehyde, glycolic acid and glyoxylic acid, also behave as reductants for this Mo-catalyzed deoxygenation of sulfoxides, thus suggesting their possible intermediacy during the reaction with glycerol. In contrast, formic acid was not significantly oxidized by the sulfoxide when submitted to the reaction conditions, and probably this acid could be the major product after reduction of an excess of sulfoxide.

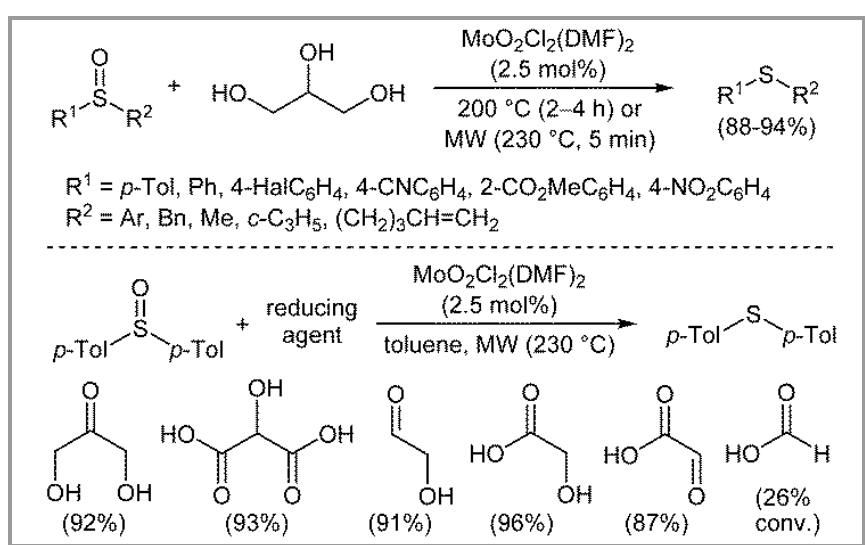

Scheme 19 Reduction of sulfoxides with glycerol and its oxidation products

Under dioxomolybdenum(VI)-catalysis, pinacol also behaves as a highly chemoselective deoxygenating reagent for a wide variety of $\mathrm{N}$-oxides such as pyridine, quinoline and isoquinoline $\mathrm{N}$-oxides, benzofuroxans, $2 \mathrm{H}$-imidazole 1 -oxides, triazole $\mathrm{N}$ oxides and even aniline $N$-oxides (Scheme 20). ${ }^{49}$ Reactions are usually very clean allowing the isolation of the pure heteroaromatics in high yields after simple extraction. In addition, $N$-hydroxybenzotriazoles, useful precursors of benzotriazoles and easily accessed from $o$-halonitroaromatics, can be also successfully reduced with the pinacol $/ \mathrm{MoO}_{2} \mathrm{Cl}_{2}(\mathrm{DMF})_{2}$ system (Scheme 20). ${ }^{49}$ The successful reduction of the $\mathrm{N}-\mathrm{OH}$ bond in these compounds is likely due to a prototropy that leads to a $\mathrm{N}$-oxide tautomer. Functional groups such as halogens, alkoxy, carbonyl, ester, carboxylic acid and nitro are well-tolerated, whereas sulfoxide competes moderately with the reduction of the $\mathrm{N}$-oxide. Again, reactions can be performed under microwave irradiation shortening reaction times.

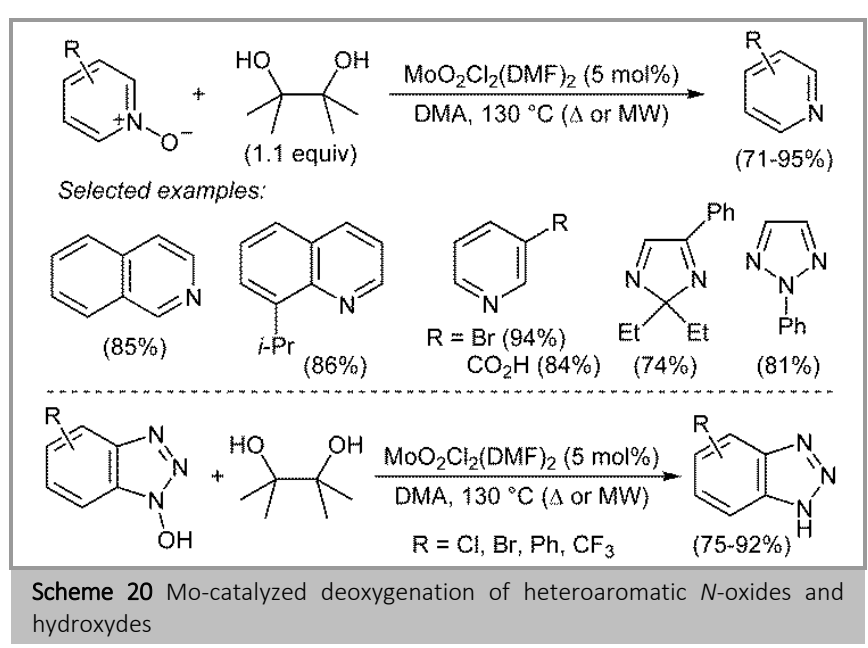

Considering that nitroaromatics are readily available and inexpensive nitrogen sources, we envisaged to merge their previously described reduction with pinacol (see Scheme 18) with subsequent imine formation that could be followed by further transformations such as intramolecular cyclizations, when starting from appropriately ortho-substituted nitroarenes. Moreover, other glycols were thought to serve as reducing agents and our group also anticipated that the carbonyl derivative, generated as waste reduction byproduct from the glycol in the first step, could be utilized for the following imine 
formation (Scheme 21).50 A selection of 1-(2nitrophenyl)pyrroles and indoles were treated with a variety of secondary and tertiary glycols, in the presence of catalytic amounts of $\mathrm{MoO}_{2} \mathrm{Cl}_{2}$ (DMF) $)_{2}$ and substiochiometric quantities of $p$-toluenesulfonic acid to favour the cyclization and further oxidation, yielding interesting pyrrolo- and indoloquinoxaline derivatives in good to high yields (Scheme 21). This methodology represents the first example in which the waste byproduct of a reaction is used as a reactant for the next step and incorporated into the final product. ${ }^{51}$

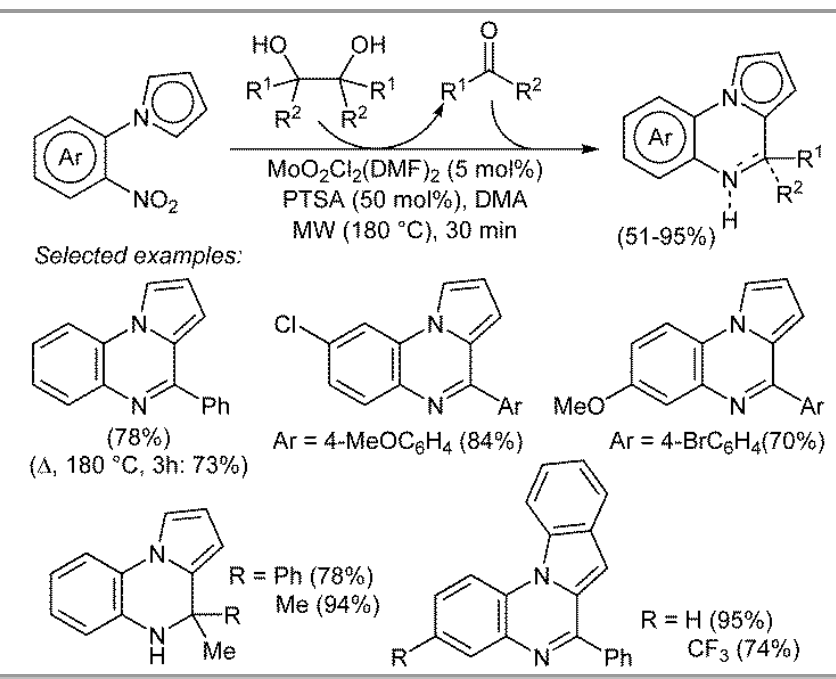

Scheme 21 Synthesis of nitrogenated polyheterocycles from nitroarenes and glycols with incorporation of waste reduction byproduct

Following this strategy, Sanz and co-workers have recently developed a sustainable variant of the Friedländer synthesis of quinolines (Scheme 22). ${ }^{52}$ Starting from easily available 2nitrophenyl aldehydes or ketones and di-tertiary glycols, under dioxomolybdenum-catalysis, a wide variety of polysubstituted quinolines have been efficiently prepared. Again, a domino process in which the waste byproduct of the initial reduction is used as a reactant for the next step and embodied into the final product, accounts for the obtained result. Using nitrobenzaldehydes, the Mo catalyst is able to promote the nitro reduction, imine generation and final condensation, whereas for $o$-nitrophenyl ketones the relay action of Mo and a Lewis acid, $\mathrm{Sc}(\mathrm{OTf})_{3}$, is required (Scheme 22).

$$
\overbrace{\mathrm{NO}_{2}}^{2}
$$

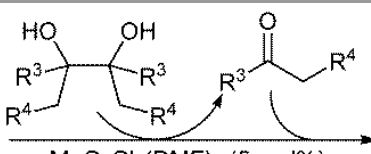

$\mathrm{MoO}_{2} \mathrm{Cl}_{2}(\mathrm{DM} F)_{2}(5 \mathrm{~mol} \%)$ DMA, MW $\left(180^{\circ} \mathrm{C}\right), 20-60 \mathrm{~min}$ for $\mathrm{R}^{2} \neq \mathrm{H}_{\mathrm{F}} \mathrm{Sc}(\mathrm{OTf})_{3}(5 \mathrm{~mol} \%)$

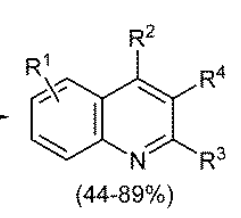

Selected examples<smiles>[R]c1ccc2ccc(-c3ccccc3)nc2c1</smiles><smiles>[R]c1cc2cc(Cl)ccc2nc1[R]</smiles>

$R^{3}=\operatorname{Me} ; R^{4}=H(85 \%)$

$R^{3}=\mathrm{Ph} ; \mathbf{R}^{4}=\mathrm{Me}(68 \%)$

$R^{3}=E t ; R^{4}=\operatorname{Me}(72 \%)$

$\mathrm{R}^{3}-\mathrm{R}^{4}=-\left(\mathrm{CH}_{2}\right)_{3}-(74 \%)$

$R^{3}=2-T h ; R^{4}=H(50 \%)$

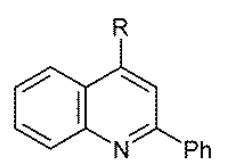

$\mathrm{R}=\mathrm{Me}(57 \%)$ $\mathrm{CF}_{3}(62 \%)$
$\mathrm{CF}_{3}(7$

Scheme 22 Mo-catalyzed Friedländer synthesis of quinolines

A slightly different reactivity, also framed in the context of the study of deoxydehydrations (DODH) of glycols, i.e. the removing of the two adjacent hydroxyl groups to afford alkenes, was disclosed by Fristrup and co-workers, who have pioneered the use of molybdenum catalysts, mainly ammonium molybdate tetrahydrate, as a greener and cheaper alternative to rheniumbased catalysts. They have described both the DODH of diols in which half the diol undergoes DODH to the corresponding alkene while the other half evolves through oxidative cleavage, ${ }^{53}$ and the DODH of diols to alkenes using $i-\mathrm{PrOH}$ as solvent and reductant, requiring high temperatures $\left(>200{ }^{\circ} \mathrm{C}\right.$ ) (Scheme 23)..$^{54}$ Wondering why our reduction of sulfoxides with pinacol worked at lower temperatures and in the absence of DODH of pinacol, these authors carried out some DFT calculations. 55 This study supported the initial formation of a pinacolate complex. They found that the energy barrier for the cleavage of pinacol was significantly lower than the corresponding one for the cleavage of 1,2-propanediol, thus accounting for the lower temperatures required in our case. However, the lack of DODH was attributed to the nature of the catalyst, as the diolate cleavage resulted to be possible and very easily achieved (2.1 kcal $\mathrm{mol}^{-1}$ ) from a monodiolate dichloride complex, what we had postulated in our mechanistic proposal, in contrast to a pure oxomolybdenum catalyst without chlorine ligands. The energy barrier $\left(\sim 40 \mathrm{kcal} \mathrm{mol}^{-1}\right)$ for the formation of a Mo(IV) pinacolate intermediate, needed for the subsequent alkene extrusion, was too high thus explaining the observed absence of DODH in our catalytic system.

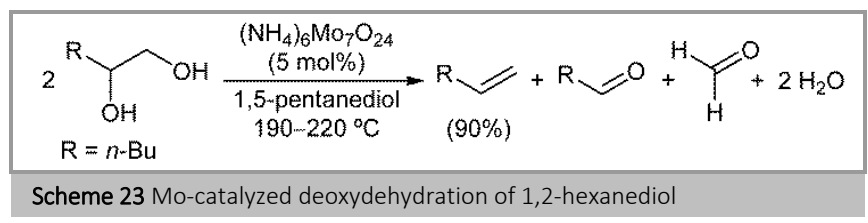

\subsection{Oxidation Reactions}

Since the development of the oxomolybdenum(VI)-catalyzed epoxidation of olefins with hydroperoxides ${ }^{56}$ (Halcon and Arco processes), a wide variety of $\mathrm{MoO}_{2} \mathrm{Cl}_{2}(\mathrm{~L})_{\mathrm{n}}$ complexes have been typically tested as catalysts, or precatalysts, for the epoxidation of alkenes, commonly employing TBHP as the stoichiometric oxidant. Due to their Lewis acidity, these complexes usually possess a high catalytic activity. However, lower selectivities are obtained for sensitive epoxides and so, in most of the reported examples, only simple susbtrates such as cis-cyclooctene or $\beta$ methystyrenes, provide good results in terms of activity and selectivity. Some of the $\mathrm{MoO}_{2} \mathrm{Cl}_{2}(\mathrm{~L})_{\mathrm{n}}$ complexes employed for the racemic epoxidation of cyclooctene are shown in Scheme 25.57 Theoretical calculations and experimental results reported by Kühn and co-workers with complexes bearing ligands like bipyridines and diazabutadienes, support a mechanism initiated by the transfer of the hydroperoxide proton to the $\mathrm{Mo}=0$ bond and the coordination of the $t$ - $\mathrm{BuOO}^{-}$group to Mo yielding a $\eta^{1-}$ alkylperoxomolybdenum(VI) complex. This complex acts as a Lewis acid increasing the oxidizing power of the peroxo group. After its approach to the $\alpha$-oxygen atom, the olefin is epoxidized by nucleophilic attack on the electrophilic oxygen. The byproduct $t$ - $\mathrm{BuOH}$ competes with TBHP for the attack to the 
metal, thereby leading to reduction of the catalytic activity (Scheme 24).58

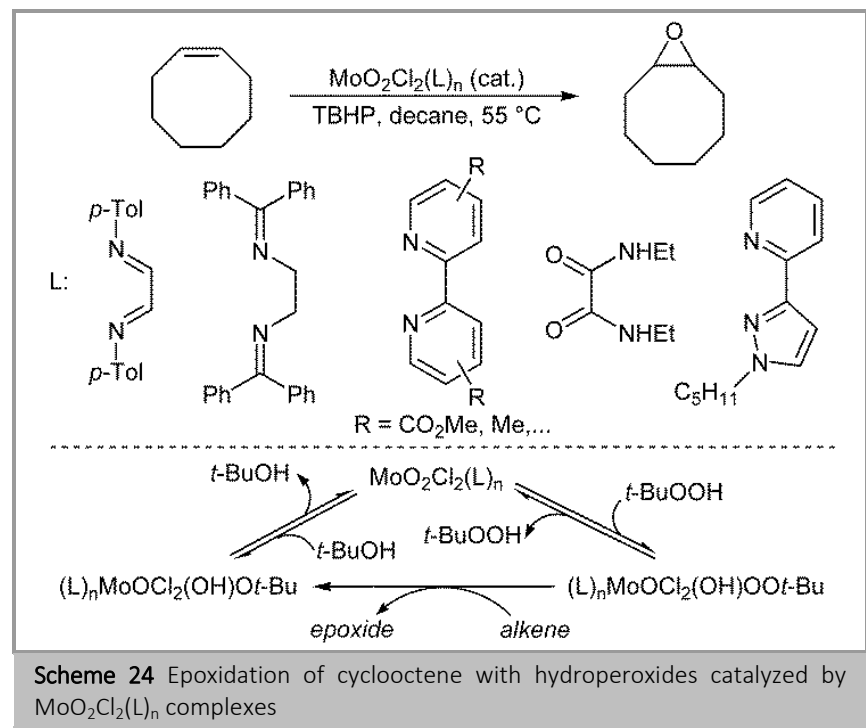

In addition, many efforts have been made in the field of asymmetric epoxidation by using $\mathrm{MoO}_{2} \mathrm{Cl}_{2} \mathrm{~L}^{*}$ complexes with a selection of chiral Lewis base ligands. ${ }^{59}$ However, the major drawback of most of these reports is the weak coordination of the chiral ligand to the metal centre, which leads to high ee only at very low conversion and finally to generally low ee.

On the other hand, the selective oxidation of thiols to disulfides is a useful transformation that can be promoted by a wide variety of oxidizing agents. In this field, Sanz and coworkers developed a simple and selective procedure that employs DMSO as oxidant under $\mathrm{MoO}_{2} \mathrm{Cl}_{2}$ (DMSO) $)_{2}$ catalysis (Scheme 25). ${ }^{60}$ The reactions proceed at room temperature and with almost quantitative yields for aromatic thiols, whereas a higher temperature is required for alkyl thiols. On the other hand, Chand and Jeyakumar described the $\mathrm{MoO}_{2} \mathrm{Cl}_{2}$-catalyzed selective oxidation of sulfides to sulfoxides or sulfones, by adjusting the quantity of the oxidizing agent, $\mathrm{H}_{2} \mathrm{O}_{2}$ (Scheme 25). ${ }^{61}$ Functional groups such as bromo, nitro, alkene, alkyne, alcohol, aldehyde, ester, or even oxime are tolerated.

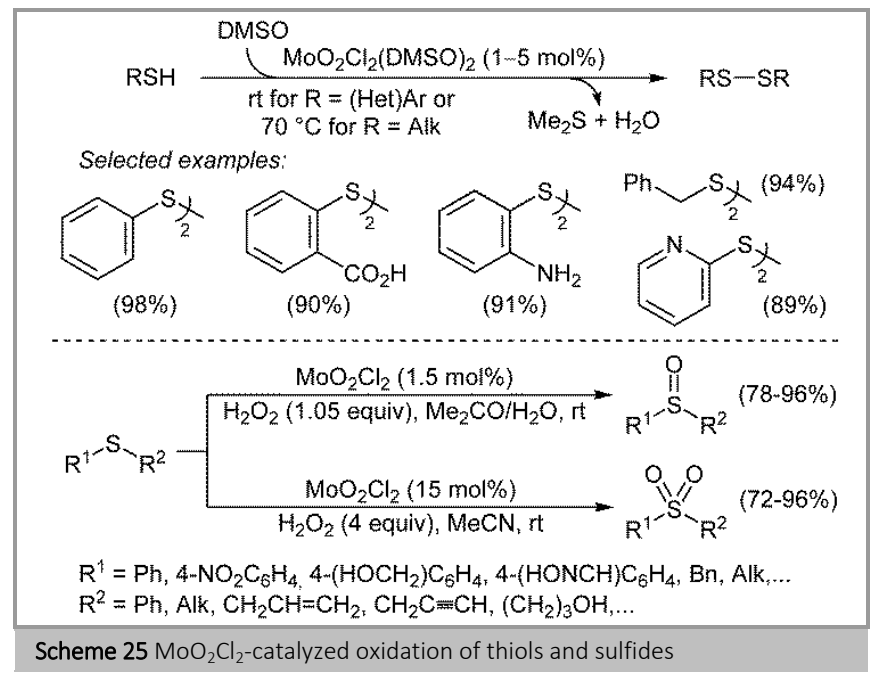

Considering the challenging chemoselective oxidation of sulfides in the presence of boronic acids or esters, Gozin and coworkers reported the sulfoxidation of thioarylboronic acids and esters using nitrate salts as oxidants and a catalytic system formed by $\mathrm{MoO}_{2} \mathrm{Cl}_{2}\left(\mathrm{OPPh}_{3}\right)_{2}$ and $\mathrm{Cu}\left(\mathrm{NO}_{3}\right)_{2}$ (Scheme 26). ${ }^{62} \mathrm{NMR}$ analysis indicated that the thioether is oxidized by nitrate, which generates nitrite. In some cases, the sulfoxidation is dramatically improved in the presence of the copper salt, whose role seems to be the inhibition of a competitive binding of the sulfoxide to the Mo center, thus preventing its subsequent reduction to the sulfide. In addition, no overoxidation to the corresponding sulfones was observed.

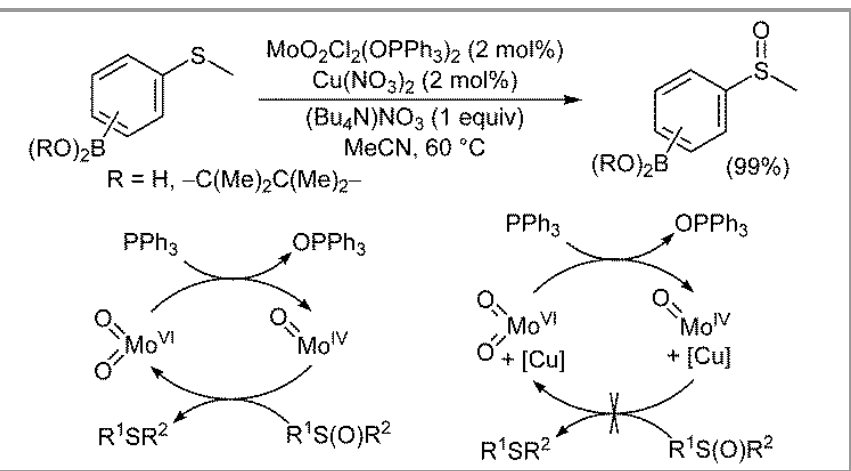

Scheme 26 Chemoselective oxidation of sulfides with nitrate salts catalyzed by a Mo-Cu system

Chand and Jeyakumar have also reported the selective aerobic oxidation of electron-rich primary benzylic alcohols and secondary benzylic alcohols to the corresponding benzaldehydes and ketones (Scheme 27).63 Reactions are catalyzed by $\mathrm{MoO}_{2} \mathrm{Cl}_{2}$ (DMSO) 2 and carried out under reflux in MeCN with bubbling of oxygen. In the proposed mechanism, an initial addition of the $\mathrm{OH}$ group across a $\mathrm{Mo}=0$ bond would take place and, upon generation of the carbonyl product a reduced Mo(IV) species would be generated and could be reoxidized by oxygen (Scheme 27). However, the presence of electronreleasing groups is mandatory in the case of primary benzylic alcohols. This drawback was solved by using a Mo-Cu catalytic system, in which supposedly, the Mo(IV) species could be reoxidized by $\mathrm{Cu}(\mathrm{II})$, whereas the $\mathrm{Cu}(\mathrm{I})$ species so formed would be reoxidized by oxygen (Scheme 27). ${ }^{63 \mathrm{~b}}$ The same authors have later developed a $\mathrm{MoO}_{2} \mathrm{Cl}_{2}$-catalyzed oxidation of $\beta$ hydroxycarbonlyl into $\alpha$-bromo 1,3-dicarbonyls with NBS (Scheme 27). ${ }^{64}$ With one equiv of NBS, the Mo complex also catalyzes the bromination of 1,3-dicarbonyls. 


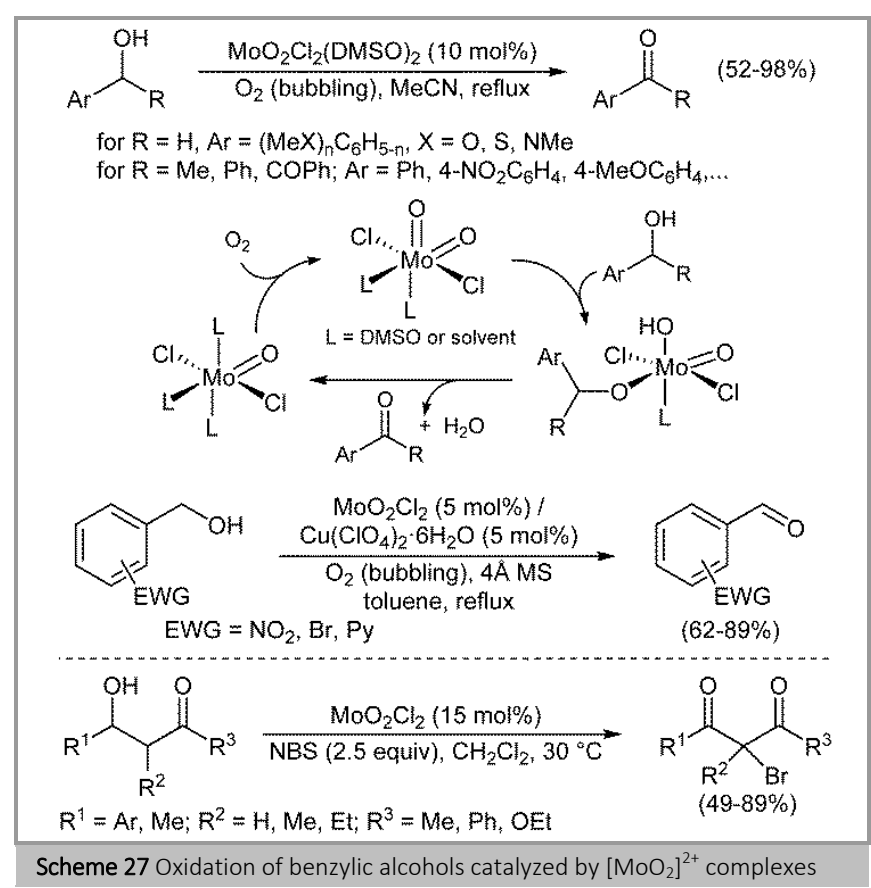

Taking advantage of the fact that pinacol is able to reduce sulfoxides under dioxomolybdenum-catalysis (see Scheme 17), our group envisaged that a simple sulfoxide, like DMSO, should behave as a new and environmentally friendly reagent for the oxidative cleavage of glycols. So, a new procedure for this reaction was developed using DMSO as solvent and reagent, and $\mathrm{MoO}_{2} \mathrm{Cl}_{2}$ (DMSO) 2 as catalyst (Scheme 28). ${ }^{65} \mathrm{~A}$ wide variety of 1,2-diols could be cleaved provided that one of the hydroxyl group was activated, i.e. secondary benzylic or tertiary. No overoxidation to the corresponding carboxylic acids was observed for secondary alcohols. In addition, acyloins could be selectively oxidized to 1,2-diketones with the DMSO/Mo system.

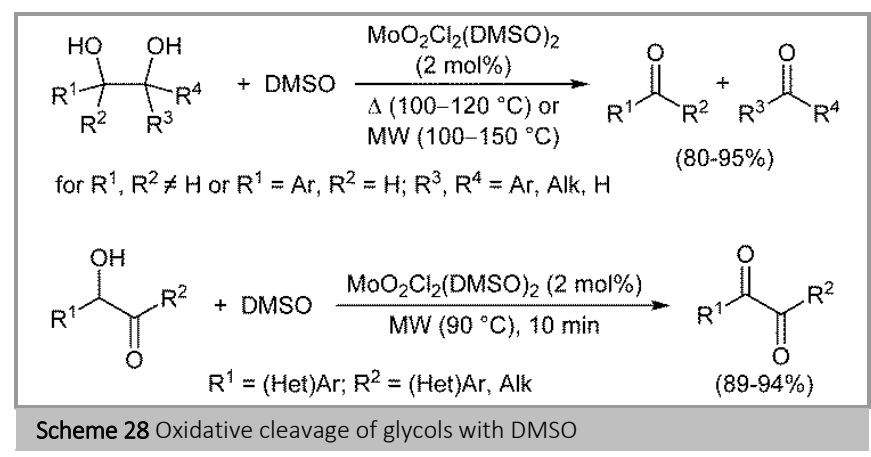

\section{Ambiphilic Reactivity of $\mathrm{MoO}_{2} \mathrm{Cl}_{2}$}

\subsection{Amphoteric Lewis Acid-Lewis Base Catalyzed Reactions}

In dioxomolybdenum(VI) complexes the partially positively charged Mo in the $M o=0$ entities, along with the presence of unoccupied low-energy orbitals, causes the metal center to be Lewis acidic. On the other hand, the partially negatively charged 0 , and its lone pairs, renders the oxygen atom as a Lewis base. Therefore, the $\mathrm{Mo}=0$ units have a potentially amphoteric nature $\left({ }^{+} \mathrm{Mo}-\mathrm{O}^{-}\right)$, being an example of a Lewis acid-Lewis base conjugate catalyst with the acidic and basic elements stereoelectronically connected through monoconjugation (type B-1 according with Ishihara's classification). ${ }^{66}$ In this field, and after having described the catalytic nucleophilic acyl substitution (NAS) of anhydrides catalyzed by amphoteric $\mathrm{V}(\mathrm{O})(\mathrm{OTf})_{2}{ }^{67}$ Chen and co-workers also showed that $\mathrm{MoO}_{2} \mathrm{Cl}_{2}$ was the most active catalyst among group VIb to promote NAS of anhydrides with a wide variety of nucleophiles (alcohols, amines, and thiols). The corresponding acylated compounds were obtained in high yields (Scheme 29).68 The amphoteric character of the $\mathrm{Mo}=0$ unit is responsible for the catalytic activity, and control experiments showed that an oxomolybdenum dialkanoate intermediate is involved, which derives from a NAS of an anhydride with a ${ }^{+} \mathrm{Mo}^{-} \mathrm{O}^{-}$unit, and is subsequently attacked by the protic nucleophile. A challenging chemoselective acylation of 2-amino-2-methyl-1-propanol has also been achieved under these conditions (Scheme 29).

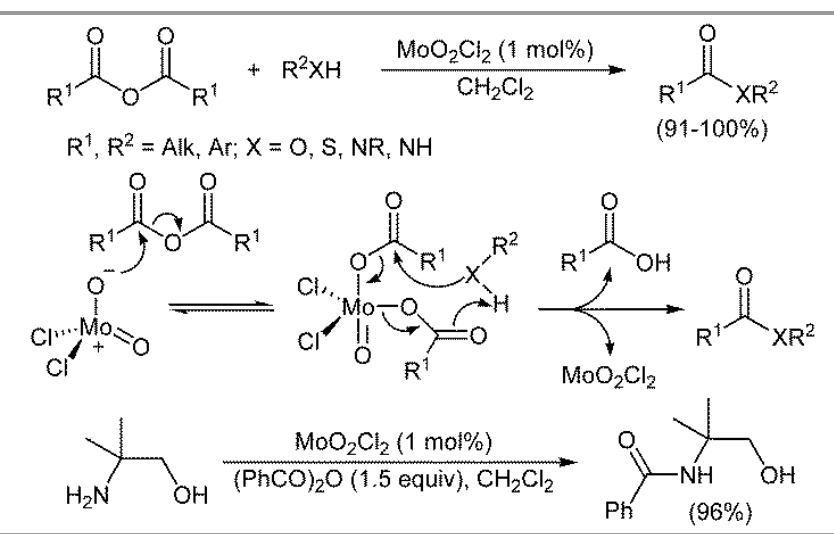
Scheme 29 Nucleophilic acyl substitutions of anhydrides catalyzed by amphoteric $\mathrm{MoO}_{2} \mathrm{Cl}_{2}$

The same authors have described mild and chemoselective procedures for acetalyzation ${ }^{69}$ and thioglycosylation ${ }^{70}$ of monosacharides taking advantage of the amphoteric nature of the $\mathrm{M}=0$ unit in oxomolybdenum and oxovanadium complexes. The thioglycosylation of $O$-acetylated glycosides yielded 1,2trans-thioglycosides with exquisite diastereocontrol (Scheme 30). Starting from D-glucose, $\mathrm{MoO}_{2} \mathrm{Cl}_{2}$ proved to be able to catalyze a four step sequence involving peracetylationthioglycosylation-deacylation-acetal formation in $\sim 75 \%$ overall yield without purification of any intermediate (Scheme 30). Later on, Varela and co-workers described that $\mathrm{MoO}_{2} \mathrm{Cl}_{2}$ could also promote the thioglycosylation of the thiol group of 6thiosugars by per- $O$-acylfuranose yielding a thiodisaccharide with complete 1,2-trans diastereocontrol (Scheme 30). ${ }^{71}$ 


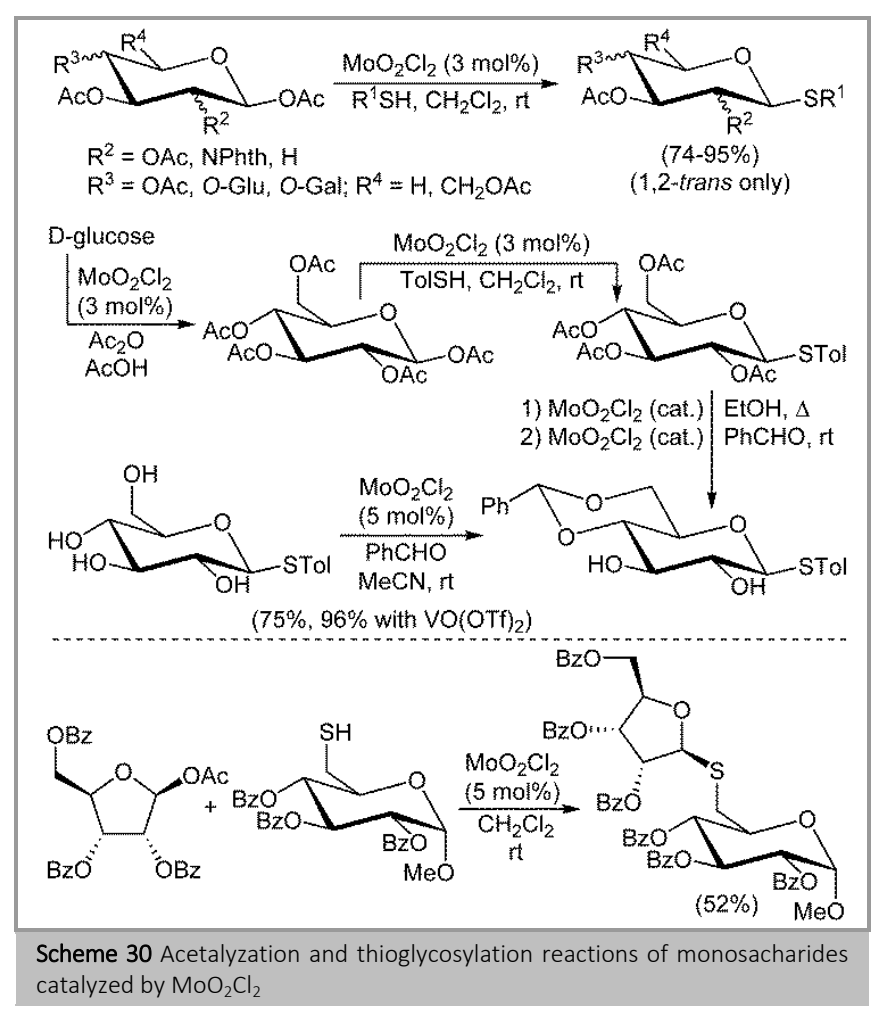

Chen and co-workers have also evidenced that $\mathrm{MoO}_{2} \mathrm{Cl}_{2}$ shows remarkable catalytic activity for the deacylation of esters in methanol. Highly chemoselective processes were achieved for functionalized substrates possessing different ester or ether groups (Scheme 31). ${ }^{72}$ In addition, peracylated monosaccharides could be selectively deacetylated, even in the presence of benzoate or pivalate groups, reacting primary acetates faster than secondary ones.

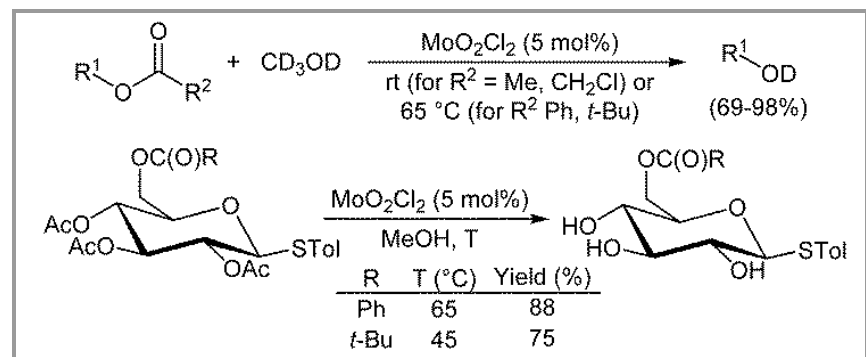

Scheme 31 Chemoselective deacylation reactions of functionalized esters

Related to this, Abrantes and co-workers have shown that several dioxomolybdenum(VI) complexes, such as $\mathrm{MoO}_{2} \mathrm{Cl}_{2}(\mathrm{DMF})_{2}, \mathrm{MoO}_{2} \mathrm{Cl}_{2}$, or $\mathrm{MoO}_{2} \mathrm{Cl}_{2}$ (bpy), are able to promote the phosphoester hydrolysis of model $p$ nitrophenylphosphate. ${ }^{73}$

\subsection{Lewis Acid-Type Catalyzed Reactions}

High-valent oxomolybdenum complexes like $\mathrm{MoO}_{2} \mathrm{Cl}_{2}$ are coordinatively unsaturated and can be considered as hard Lewis acids susceptible to activate hard Lewis bases. For instance, the ring opening of epoxides by water or alcohols is a useful organic transformation for accessing 1,2-diol derivatives, that usually requires to be either base or acid catalyzed. Cole-Hamilton and co-workers reported that $\mathrm{MoO}_{2} \mathrm{Cl}_{2} \mathrm{~L}$, bearing a $\beta$ ketophosphonate derived from camphor as a neutral ligand, catalyzes the selective attack of water to cis-limonene oxide to yield the trans-diaxial diol, whereas the trans isomer remains unreacted, thus allowing its kinetic separation (Scheme 32). ${ }^{74}$ In an analogous way, Chand and Jeyakumar have reported the transformation of epoxides to $\beta$-alkoxy alcohols, acetonides, and $\alpha$-alkoxy ketones under $\mathrm{MoO}_{2} \mathrm{Cl}_{2}$-catalysis. With unsymmetrical epoxides the nucleophilic attack takes place at the $\beta$-position, except with styrene oxide that affords 2-methoxyphenylethanol upon methanolysis (Scheme 32). ${ }^{75}$ Direct conversion of epoxides into acetonides also takes place efficiently in the presence of acetone at $50^{\circ} \mathrm{C}$. In addition, $\alpha$-alkoxy ketones can be also obtained from epoxides by adding oxone to the $\mathrm{MeOH} / \mathrm{MoO}_{2} \mathrm{Cl}_{2}$ catalytic system (Scheme 32). These reactions are highly chemoselective as several sensitive functional groups are tolerated under these mild reaction conditions. In the proposed mechanism, the first step would involve coordination of the epoxide to $\mathrm{MoO}_{2} \mathrm{Cl}_{2}$ activating the former for the subsequent nucleophilic attack. More recently, it has been reported that $\mathrm{MoO}_{2} \mathrm{Cl}_{2} \mathrm{~L}$ ( $\mathrm{L}=4,4^{\prime}$-di-t-butyl-2,2'-bipyridine) is also a useful precatalyst for the ethanolysis of styrene oxide. ${ }^{76}$

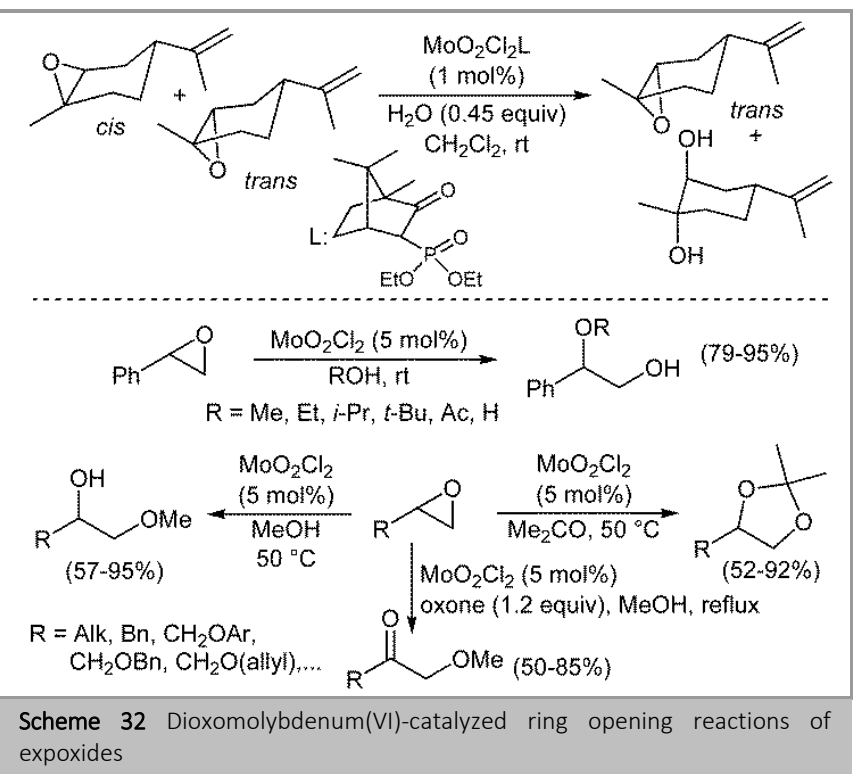

In this area, a tandem epoxidation/solvolysis of glucal and galactal derivatives with TBHP as oxidant was carried out by Castillón, Díaz and co-workers using $\mathrm{MoO}_{2} \mathrm{Cl}_{2}$ or $\mathrm{MoO}_{2}$ (acac) 2 as catalysts. Different degrees of selectivity were obtained depending on the nature of the starting glycals and their susbstituents. ${ }^{77}$

Chand and Jeyakumar have successfully used $\mathrm{MoO}_{2} \mathrm{Cl}_{2}$ as catalyst for the synthesis of $\beta$-ketoesters by reacting aldehydes with ethyl diazoacetate (Scheme 33). ${ }^{78}$ Interestingly, no side products, like 2-aryl-3-hydroxy-2-acrylic esters, were obtained under the reported conditions. Activation of the aldehyde by acidic $\mathrm{MoO}_{2} \mathrm{Cl}_{2}$ would favour the nucleophilic attack of the diazoacetate, whereas a subsequent 1,2-hydride migration with loss of $\mathrm{N}_{2}$ would yield the $\beta$-ketoester. Both (hetero)aryl and aliphatic aldehydes afforded the products in high yields. 


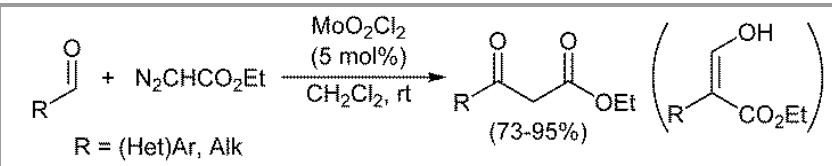

Scheme 33 Synthesis of $\beta$-keto esters from ethyl diazoacetate and aldehydes

Moreover, Goswami and Maity described a mild and simple method for the thioacetalization of (hetero)aryl and alkyl aldehydes. This strategy was applied to the preparation of challenging pterin thioacetals (Scheme 34$)^{79}$ and was also effective with acetals instead of aldehydes. Related thioacetalizations had been previously found by Roy and coworkers using $\mathrm{MoO}_{2}(\mathrm{acac})_{2}$ as catalyst. 80

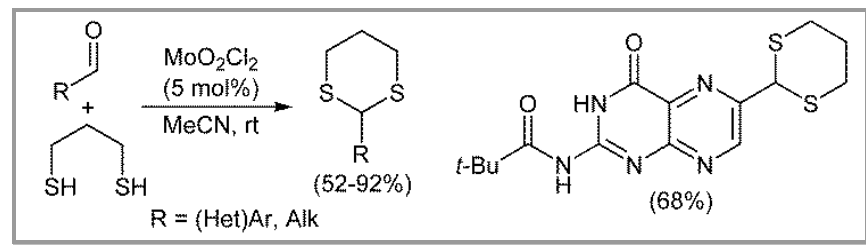

Scheme $34 \mathrm{MoO}_{2} \mathrm{Cl}_{2}$-catalyzed thioacetalization of aldehydes

Fernandes and co-workers have reported the use of $\mathrm{MoO}_{2} \mathrm{Cl}_{2}$ as catalyst for Friedel-Crafts acylation and sulfonylation reactions for the synthesis of aromatic ketones and sulfones, respectively (Scheme 35). ${ }^{81}$ Moderate to good yields were obtained under solvent-free conditions for a variety of aromatics such as (thio)anisoles, $p$-xylene, toluene or thiophene, although high loads of the catalyst were required and low regiocontrol was observed. Activation of the acyl or sulfonyl chloride could take place through coordination of the $\mathrm{C}=\mathrm{O}$ or $\mathrm{S}=0$ groups to the metal vacant sites or through addition of $\mathrm{C}(\mathrm{O})-\mathrm{Cl}$ or $\mathrm{S}(\mathrm{O})_{2}-\mathrm{Cl}$ bonds across the $\mathrm{Mo}=0$ unit, similar to the activation of anhydrides (see Scheme 29).

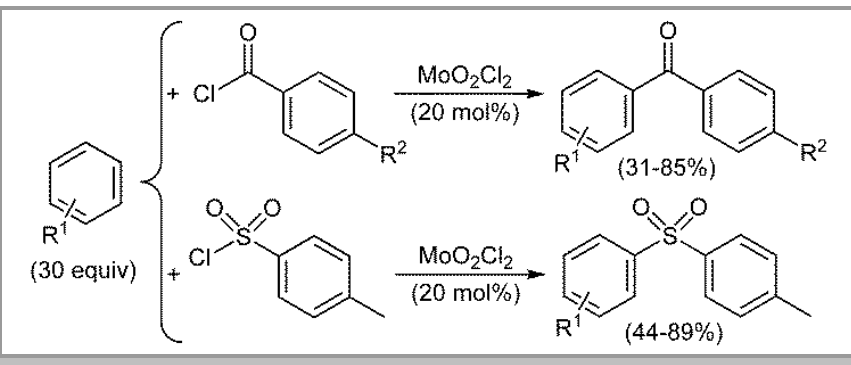

Scheme $35 \mathrm{MoO}_{2} \mathrm{Cl}_{2}$-catalyzed acylation and sulfonylation reactions

On the other hand, Stock and Brückner have found that catalytic amounts as low as $0.1 \mathrm{~mol} \%$ of $\mathrm{MoO}_{2} \mathrm{Cl}_{2}(\mathrm{DMF})_{2}$ promote the carbamate formation from alcohols and isocyanates (Scheme 36). ${ }^{82}$ A myriad array of carbamates were synthesized with almost quantitative yields in short reaction times. Only tertiary alcohols required longer times or higher catalyst loadings to achieve high yields. In addition, mild reaction conditions allowed the employment of this procedure with polyfunctional susbtrates. Moreover, diols and oligools reacted with monoisocyanates to yield the respective di and oligocarbamates, as did simple alcohols with diisocyanates to provide access to the corresponding dicarbamates. Carbamate formation was explained by considering an initial [2+2]cycloaddition of the isocyanate with a $M o=0$ unit leading to a molybda-1,3-oxazetidinone, which upon addition of the alcohol to the $\mathrm{C}=\mathrm{O}$ group would give rise to a tetrahedral intermediate. Finally, this could be broken down by a $[2+2]$-cycloreversion regenerating the catalyst and releasing, after tautomerization, the final carbamate (Scheme 36).

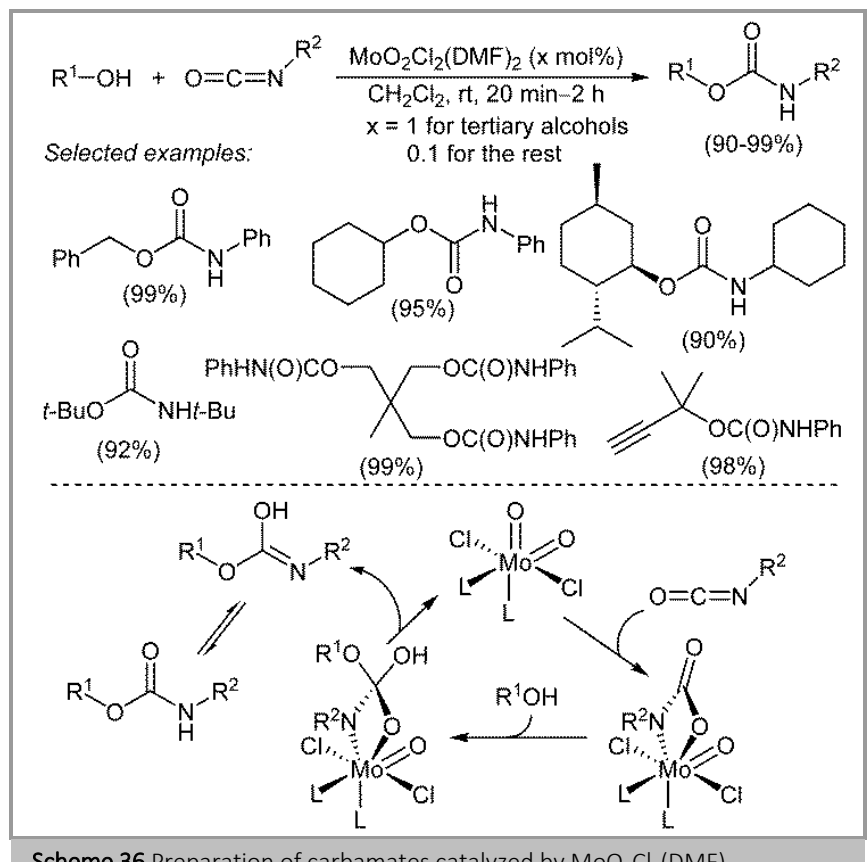

Scheme 36 Preparation of carbamates catalyzed by $\mathrm{MoO}_{2} \mathrm{Cl}_{2}(\mathrm{DMF})_{2}$

In this field, Calhorda, Fernandes and co-workers have disclosed the use of $\mathrm{MoO}_{2} \mathrm{Cl}_{2}$ as catalyst for the hydrophosphonylation of both aldehydes ${ }^{83}$ and imines ${ }^{84}$ with diethylphosphite to yield $\alpha$-hydroxyphosphonates and $\alpha$ aminophosphonates, respectively (Scheme 37). Excellent yields of a variety of phosphonates were obtained under solvent-free conditions. This reaction is highly chemoselective as different functional groups, like nitro, trifluoromethyl, ester, or cyano, are well-tolerated. However, better yields are obtained and shorter reaction times are required when electron-withdrawing groups are present. Based on DFT studies, ${ }^{44 a}$ a mechanism was proposed in which the $\mathrm{P}=\mathrm{O}$ unit would coordinate to Mo and the hydrogen atom from $\mathrm{P}-\mathrm{H}$ would be transferred to one $\mathrm{Mo}=0$ entity, i.e. a formal $[3+2]$ addition of $\mathrm{H}$ and $\mathrm{O}$ atoms of $\mathrm{HP}(\mathrm{O})(\mathrm{OEt})_{2}$ to the $\mathrm{Mo}=0$. Then, the aldehyde or the imine would bind the metal leading to formation of a $\mathrm{P}-\mathrm{C}$ bond. Finally, the $\mathrm{H}$ atom would be transferred from $\mathrm{Mo}-\mathrm{OH}$ to the final product (Scheme 37). 


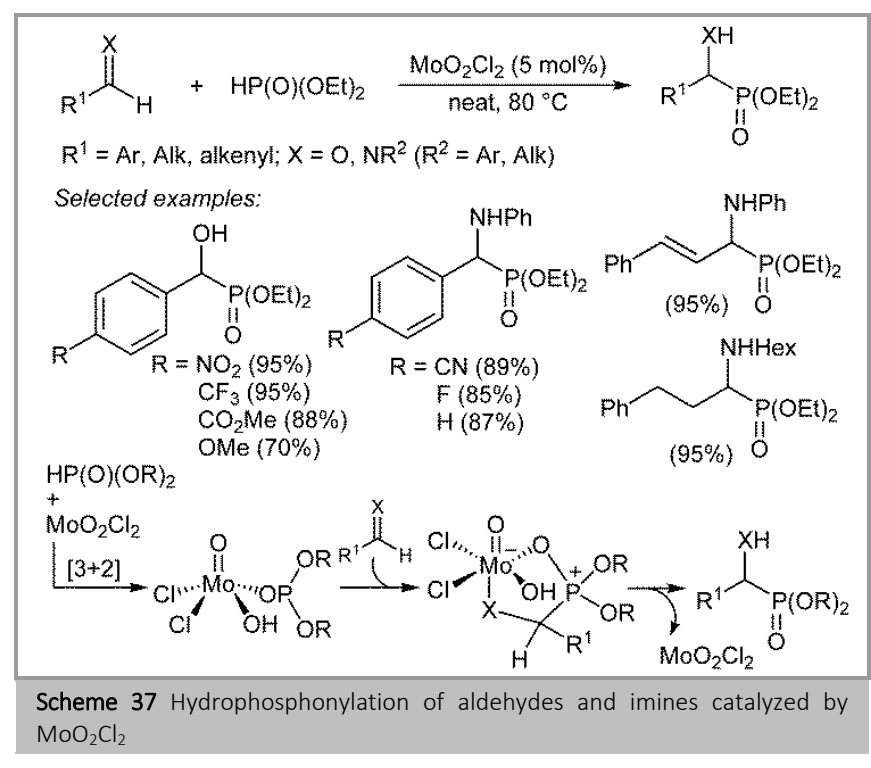

Exploiting the Lewis acidic character of $\mathrm{MoO}_{2} \mathrm{Cl}_{2}$, Babu and co-workers have developed an efficient synthesis of 3,4dihydropyrimidin(thi)ones and polyhydroquinones through Biginelli and Hantzsch reactions, respectively (Scheme 38)..$^{85}$ Acid-sensitive groups like silyl ethers are well-tolerated and reactions take place in good yields and short reaction times. Gram-scale processes are possible and, in addition, the catalyst could be reused.

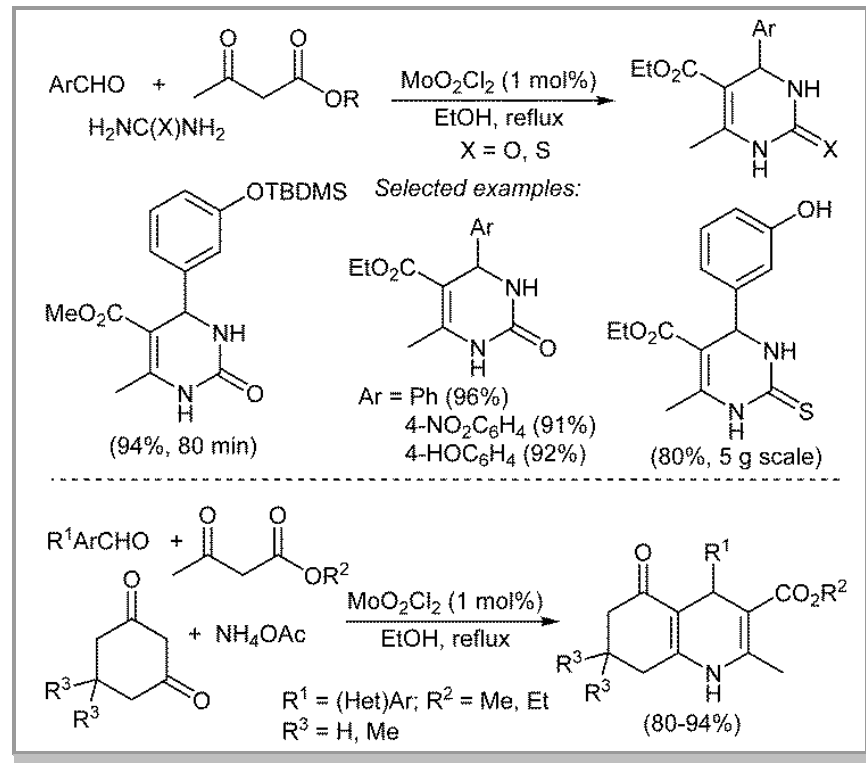

Scheme $38 \mathrm{MoO}_{2} \mathrm{Cl}_{2}$-catalyzed Biginelli and Hantzsch reactions.

Finally, in the context of sustainable production of platform chemicals from biomass, Fernandes and co-workers have reported the Mo-catalyzed one-pot synthesis of 5ethoxymethylfurfural (EMF) and 5-hydroxymethylfurfural (HMF) from renewable carbohydrates. ${ }^{86}$ The developed procedure allows the preparation of EMF (53-60\%) and HMF (75\%) from fructose (Scheme 39).

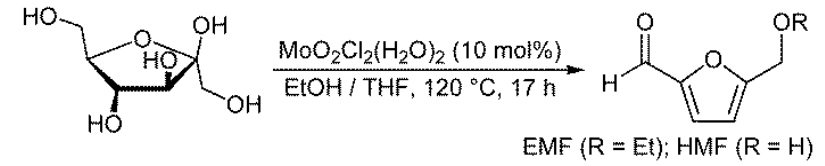

Scheme 39 Mo-catalyzed synthesis of furfural-based platform chemicals from carbohydrates

\section{Conclusion and Perspective}

$\mathrm{MoO}_{2} \mathrm{Cl}_{2}$ and its addition compounds $\mathrm{MoO}_{2} \mathrm{Cl}_{2}(\mathrm{~L})_{\mathrm{n}}$ are commercially or easily available metal complexes based on nonnoble, relatively abundant, non-expensive, and less toxic molybdenum. As evidenced by the examples discussed in this review, a wide variety of organic transformations can be catalyzed by these complexes being reduction and deoxygenation of organic compounds the most relevant and distinctive processes. In addition, both the amphoteric Lewis acid-Lewis base character of the $\mathrm{Mo}=0$ units and the inherent Lewis acid nature of high valent metal oxido fragments account for a less remarkable but also useful reactivity.

Given their potential as OAT catalysts and highly selective Lewis acids, in the next years we can expect dichlorodioxomolybdenum(VI) complexes to experiment a growing development and application in organic synthesis. Regarding reduction and deoxygenation processes, new possible stoichiometric reducing agents may be found and exploited. Moreover, another area currently in progress is supported molybdenum complexes, which may find synthetic purpose and convenience in the field.

\section{Funding Information}

Financial support from Ministerio de Economía y Competitividad (MINECO) (CTQ2016-48937-C2-1-P) and Junta de Castilla y León and FEDER (BU076U16) is gratefully acknowledged.

\section{Acknowledgment}

As far as our contributions are concerned, we thank our co-workers, Dra. M. R. Pedrosa, Dr. M. A. Fernández-Rodríguez, Dra. P. García-García, Dr. S. Suárez-Pantiga, Dra. N. García, Dr. R. Rubio-Presa, and Dr. F. J. Arnáiz for their dedicated work.

\section{References}

(1) (a) Metz, S.; Thiel, W. Coord. Chem. Rev. 2011, 255, 1085. (b) Hille, R. Dalton Trans. 2013, 42, 3029.

(2) Khurana, J. M.; Chauhan, S.; Agrawal, A. Org. Prep. Proc. Int. 2004, 36, 201.

(3) For previous reviews, see: (a) Sanz, R.; Pedrosa, M. R. Curr. Org. Synth. 2009, 6, 239. (b) Jeyakumar, K.; Chand, D. K. J. Chem. Sci. 2009, 121, 111. (c) Sanz, R.; Pedrosa, M. R. Adv. Org. Synth. 2012, 4, 183.

(4) Chand, D. K.; Chakravarthy, R. D. Molybdenum Chloride Oxide, In Encyclopedia of Reagents for Organic Synthesis, Wiley, 2012.

(5) Schrock, R. R.; Murdzek, J. S.; Bazan, G. C.; Robbins, J.; DiMare, M.; O’Regan, M. J. Am. Chem. Soc. 1990, 112, 3875.

(6) Colton, R.; Tomkins, I. B. Aust. J. Chem. 1965, 18, 447 and references cited therein.

(7) (a) Arnáiz, F. J.; Aguado, R.; Sanz-Aparicio, J.; Martínez-Ripoll, M. Polyhedron 1994, 13, 2745. (b) Arnáiz, F. J. Inorg. Synth. 1997, 31, 246. 
(8) Arnáiz, F. J.; Aguado, R.; Pedros, M. R.; De Cian, A. Inorg. Chim. Acta 2003, 347, 33.

(9) (a) Butcher, R. J.; Gunz, H. P.; Maclagan, R. G. A. R.; Powell, H. K. J.; Wilkins, C. J.; Hian, Y. S. J. Chem. Soc., Dalton Trans. 1975, 1223. (b) Wang, G.; Chen, G.; Luck, R. L.; Wang, Z.; Mu, Z.; Evans, D. G.; Duan, X. Inorg. Chim. Acta 2004, 357, 3223.

(10) Rufanov, K. A.; Zarubin, D. N.; Ustynyuk, N. A.; Gourevitch, D. N.; Sundermeyer, J.; Churakov, A. V.; Howard, J. A. K. Polyhedron 2001, 20, 379.

(11) See, for instance: (a) Kühn, F. E.; Lopes, A. D.; Santos, A. M.; Herdtweck, E.; Haider, J. J.; Romão, C. C.; Gil Santos, A. J. Mol. Catal. A: Chem. 2000, 151, 147. (b) Kühn, F. E.; Santos, A. M.; Lopes, A. D.; Gonçalves, I. S.; Rodríguez-Borges, J. E.; Pillinger, M.; Romão, C. C. J. Organomet. Chem. 2001, 621, 207. (c) Groarke, M.; Gonçalves, I. S.; Herrman, W. A.; Kühn, F. E. J. Organomet. Chem. 2002, 649, 108. (d) Mas-Marzá, E.; Reis, P. M.; Peris, E.; Royo, B. J. Organomet. Chem. 2006, 691, 2708.

(12) Nemykin, V. N.; Laskin, J.; Basu, P. J. Am. Chem. Soc. 2004, 126, 8604.

(13) Enemark, J. H.; Cooney, J. J. A.; Wang, J.-J.; Holm, R. H. Chem. Rev. 2004, 104, 1175.

(14) (a) Arzoumanian, H. Coord. Chem. Rev. 1998, 178-180, 191. (b) Smith, P. D.; Millar, A. J.; Young, C. G.; Ghosh, A.; Basu, P. J. Am. Chem. Soc. 2000, 122, 9298.

(15) Castiñeira Reis, M.; Marín-Luna, M.; Silva-López, C.; Nieto-Faza, O. Inorg. Chem. 2017, 56, 10570.

(16) Kennedy-Smith, J. J.; Nolin, K. A.; Gunterman, H. P.; Toste, F. D. J. Am. Chem. Soc. 2003, 125, 4056.

(17) For a review comparing oxo-molybdenum and oxo-rhenium complexes, see: Sousa, S. C. A.; Fernandes, A. C. Coord. Chem. Rev. 2015, 284, 67.

(18) Sanz, R.; Escribano, J.; Aguado, R.; Pedrosa, M. R.; Arnáiz, F. J. Synthesis 2004, 1629.

(19) Sanz, R.; Escribano, J.; Fernández, Y.; Aguado, R.; Pedrosa, M. R.; Arnáiz, F. J. Synlett 2005, 1389.

(20) It has been reported that the reaction of $\mathrm{MoO}_{2} \mathrm{Cl}_{2}(\mathrm{DMF})_{2}$ with $\mathrm{PPh}_{3}$ affords the dinuclear species $\mathrm{Mo}_{2} \mathrm{O}_{3} \mathrm{Cl}_{4}(\mathrm{DMF})_{4}$. See: Aguado, R.; Escribano, J.; Pedrosa, M. R.; De Cian, A.; Sanz, R.; Arnáiz, F. J. Polyhedron 2007, 26, 3842.

(21) Gribble, G. W. In Indole Ring Synthesis: From Natural Products to Drug Discovery; John Wiley \& Sons: Chichester, UK, 2016, 266.

(22) Majgier-Baranowska, H.; Williams, J. D.; Li, B.; Peet, N. P. Tetrahedron Lett. 2012, 53, 4785.

(23) Freeman, A. W.; Urvoy, M.; Criswell, M. E. J. Org. Chem. 2005, 70, 5014.

(24) Sanz, R.; Escribano, J.; Pedrosa, M. R.; Aguado, R.; Arnáiz, F. J. Adv. Synth. Catal. 2007, 349, 713.

(25) (a) Yamamoto, Y.; Yamada, S.; Nishiyama, H. Adv. Synth. Catal. 2011, 353, 701. (b) Yamamoto, Y.; Ohkubo, E.; Shibuya, M. Adv. Synth. Catal. 2017, 359, 1747.

(26) Huleatt, P. B.; Lau, J.; Chua, S.; Tan, Y. L.; Duong, H. A.; Chai, C. L. L. Tetrahedron Lett. 2011, 52, 1339.

(27) Karimi, S.; Ma, S.; Liu, Y.; Ramig, K.; Greer, E. M.; Kwon, K.; Berkowitz, W. F.; Subramaniam, G. Tetrahedron Lett. 2017, 58, 2223.

(28) (a) Malakar, C. C.; Merisor, E.; Conrad, J.; Beifuss, U. Synlett 2010, 1766. (b) Moustafa, A. H.; Malakar, C. C.; Aljaar, N.; Merisor, E.; Conrad, J. Beifuss, U. Synlett 2013, 24, 1573.

(29) (a) Davies, I. W.; Guner, V. A.; Houk, K. N. Org. Lett. 2004, 6, 743. (b) Merisor, E.; Conrad, J.; Klaiber, I.; Mika, S.; Beifuss, U. Angew. Chem. Int. Ed. 2007, 46, 3353. See also ref. (27).

(30) See, for instance: (a) Zhu, Z.; Espenson, J. H. J. Mol. Catal. A: Chem. 1995, 103, 87. (b) Sousa, S. C. A.; Fernandes, A. C. Tetrahedron Lett. 2011, 52, 6960. (c) Nakagiri, T.; Murai, M.; Takai, T. Org. Lett. 2015, 17, 3346.

(31) Hills, L.; Moyano, R.; Montilla, F.; Pastor, A.; Galindo, A.; Álvarez, E.; Marchetti, F.; Pettinari, C. Eur. J. Inorg. Chem. 2013, 3352. However, a good yield was obtained using a dioxomolybdenum(VI) complex with acylpyrazolonate ligands.
(32) Asako, S.; Sakae, T.; Murai, M.; Takai, K. Adv. Synth. Catal. 2016, $358,3966$.

(33) (a) Fernandes, A. C.; Fernandes, R.; Romão, C. C.; Royo, B. Chem. Commun. 2005, 213. (b) Reis, P. M.; Romão, C. C.; Royo, B. Dalton Trans. 2006, 1842.

(34) Fernandes, A. C.; Romão, C. C. Tetrahedron Lett. 2005, 46, 8881.

(35) Smith, C. A.; Cross, L. E.; Hughes, K.; Davis, R. E.; Judd, D. B.; Merritt, A. T. Tetrahedron Lett. 2009, 50, 4906.

(36) Fernandes, A. C.; Romão, C. C. J. Mol. Catal. A: Chem. 2006, 253, 96.

(37) Fernandes, A. C.; Romão, C. C. J. Mol. Catal. A: Chem. 2007, 272, 60.

(38) Fernandes, A. C.; Romão, C. C. Tetrahedron 2006, 62, 9650.

(39) Fernandes, T. A.; Fernandes, A. C. ChemCatChem 2015, 7, 3503.

(40) (a) Costa, P. J.; Romão, C. C.; Fernandes, A. C.; Royo, B.; Reis, P. M.; Calhorda, M. J. Chem. Eur. J. 2007, 13, 3934. (b) Drees, M.; Strassner, T. Inorg. Chem. 2007, 46, 10850. (c) Ning, X.; Wang, J.; Wei, H. J. Phys. Chem. A 2016, 120, 4167. (d) Wang, Y.; Gu, P.; Wang, W.; Wei, H. Catal. Sci. Technol. 2014, 4, 43.

(41) Reis, P. M.; Costa, P. J.; Romão, C. C.; Fernandes, J. A.; Calhorda, M. J.; Royo, B. Dalton Trans. 2008, 1727.

(42) Reis, P. M.; Royo, B. Tetrahedron Lett. 2009, 50, 949.

(43) Fernandes, A. C.; Romão, C. C. Tetrahedron Lett. 2007, 48, 9176.

(44) (a) Calhorda, M. J.; Costa, P. J. Dalton Trans. 2009, 8155. (b) Huang, L.; Wei, H. New J. Chem. 2014, 38, 5421.

(45) García, N.; Fernández-Rodríguez, M. A.; García-García, P.; Pedrosa, M. R.; Arnáiz, F. J.; Sanz, R. RSC Adv. 2016, 6, 27083.

(46) García N.; García-García, P.; Fernández-Rodríguez, M. A.; Rubio, R.; Pedrosa, M. R.; Arnáiz, F. J.; Sanz, R. Adv. Synth. Catal. 2012, 354, 321.

(47) Hanson, S. K.; Baker, R. T.; Gordon, J. C.; Scott, B. L.; Sutton, A. D.; Thorn, D. L. J. Am. Chem. Soc. 2009, 131, 428.

(48) García N.; García-García, P.; Fernández-Rodríguez, M. A.; García, D.; Pedrosa, M. R.; Arnáiz, F. J.; Sanz, R. Green Chem. 2013, 15, 999.

(49) Rubio-Presa, R.; Fernández-Rodríguez, M. A.; Pedrosa, M. R.; Arnáiz, F. J.; Sanz, R. Adv. Synth. Catal. 2017, 359, 1752.

(50) Rubio-Presa, R.; Pedrosa, M. R.; Fernández-Rodríguez, M. A.; Arnáiz, F. J.; Sanz, R. Org. Lett. 2017, 19, 5470.

(51) For an excellent review of this type of strategies, see: Zhou, J.; Zeng, X.-P. In Multicatalyst System in Asymmetric Catalysis; Zhou, J., Ed.; John Wiley \& Sons: New York, 2014, 633.

(52) Rubio-Presa, R.; Suárez-Pantiga, S.; Pedrosa, M. R.; Sanz, R. Adv. Synth. Catal. 2018, 360, 2216.

(53) Dethlefsen, J. R.; Lupp, D.; Oh, B.-C.; Fristrup, P. ChemSusChem 2014, 7, 425 .

(54) Dethlefsen, J. R.; Lupp, D.; Teshome, A.; Nielsen, L. B.; Fristrup, P. ACS Catal. 2015, 5, 3638.

(55) Lupp, D.; Christensen, N. J.; Dethlefsen, J. R.; Fristrup, P. Chem. Eur. J. 2015, 21, 3435.

(56) (a) For selected reviews, see: (a) Kühn, F. E.; Zhao, J.; Herrmann, W. A. Tetrahedron: Asymmetry 2005, 16, 3469. (b) Kühn, F. E.; Santos, A. M.; Abrantes, M. Chem. Rev. 2006, 106, 2455. (c) Jain, K. R.; Herrmann, W. A.; Kühn, F. E. Coord. Chem. Rev. 2008, 252, 556.

(57) (a) Valente, A. A.; Moreira, J.; Lopes, A. D.; Pillinger, M.; Nunes, C. D.; Romão, C. C.; Kühn, F. E.; Gonçalves, I. S. New J. Chem. 2004, 28, 308. (b) Petrovski, Z.; Pillinger, M.; Valente, A. A.; Gonçalves, I. S.; Hazell, A.; Romão, C. C. J. Mol. Catal. A: Chem. 2005, 227, 67. (c) Günyar, A.; Betz, D.; Drees, M.; Herdtweck, E.; Kühn, F. E. J. Mol. Catal. A: Chem. 2010, 331, 117. (d) Amarante, T. R.; Neves, P.; Almeida-Paz, F. A.; Valente, A. A.; Pillinger, M.; Gonçalves, I. S. Dalton Trans. 2014, 43, 6059. (e) Oliveira, T. S. M.; Gomes, A. C.; Lopes, A. D.; Lourenco, J. P.; Almeida-Paz, F. A.; Pillinger, M.; Gonçalves, I. S. Dalton Trans. 2015, 44, 14139.

(58) (a) Kühn, F. E.; Groarke, M:; Bencze, E.; Herdtweck, E.; Prazeres, A.; Santos, A. M.; Calhorda, M. J.; Romão, C. C.; Gonçalves, I. S.; Lopes, A. D.; Pillinger, M. Chem. Eur. J. 2002, 8, 2370. (b) Veiros, L. F.; Prazeres, A.; Costa, P. J.; Romao, C. C.; Khün, F. E.; Calhorda, M. J. Dalton Trans. 2006, 1383.

(59) See, for instance: (a) Petrovski, Z.; Pillinger, M.; Valente, A. A.; Gonçalves, I. S.; Hazell, A.; Romão, C. C. J. Mol. Catal. A: Chem. 2005, 227, 67. (b) Gago, S.; Rodríguez-Borges, J. E.; Teixeira, C.; 
Santos, A. M.; Zhao, J.; Pillinger, M.; Nunes, C. D.; Petrovski, Z.; Santos, T. M.; Kühn, F. E.; Romão, C. C.; Gonçalves, I. S. J. Mol. Catal. A: Chem. 2005, 236, 1.

(60) Sanz, R.; Aguado, R.; Pedrosa, M. R.; Arnáiz, F. J. Synthesis 2002, 856.

(61) Jeyakumar, K.; Chand, D. K. Tetrahedron Lett. 2006, 47, 4573.

(62) Marom, H.; Antonov, S.; Popowski, Y.; Gozin, M.J. Org. Chem. 2011, 76,5240

(63) (a) Jeyakumar, K.; Chand, D. K. Appl. Organomet. Chem. 2006, 20, 840. (b) Jeyakumar, K.; Chand, D. K. Open Catal. J. 2008, 1, 6.

(64) Jeyakumar, K.; Chand, D. K. Synthesis 2009, 306.

(65) García N.; Rubio-Presa, R.; García-García, P.; FernándezRodríguez, M. A.; Pedrdosa, M. R.; Arnáiz, F. J.; Sanz, R. Green Chem. 2016, 18, 2335.

(66) Ishihara, K.; Sakakura, A.; Hatano, M. Synlett 2007, 686.

(67) Chen, C.-T.; Kuo, J.-H.; Li, C.-H.; Barhate, N. B.; Hon, S.-W.; Li, T.-W.; Chao, S.-D.; Liu, C.-C.; Li, Y.-C.; Chang, I-H.; Lin, J.-S.; Liu, C.-J.; Chou, Y-C. Org. Lett. 2001, 3, 3729.

(68) Chen, C-T.; Kuo, J.-H.; Pawar, V. D.; Munot, Y. S.; Weng, S.-S.; Ku, C.H.; Liu, C.-Y. J. Org. Chem. 2005, 70, 1188.

(69) Chen, C.-T.; Weng, S.-S.; Kao, J.-Q.; Lin, C.-C.; Jan, M.-D. Org. Lett. 2005, 7, 3343

(70) Weng, S.-S.; Lin, Y.-D.; Chen, C.-T. Org. Lett. 2006, 8, 5633.

(71) Repetto, E.; Marino, C.; Uhrig, M. L.; Varela, O. Eur. J. Org. Chem. 2008, 540

(72) Liu, C.-Y.; Chen, H.-L.; Ko, C.-M.; Chen, C.-T. Tetrahedron 2011, 67, 872 .
(73) (a) Tomé, C. M.; Oliveira, M. C.; Pillinger, M.; Gonçalves, I. S.; Abrantes, M. Dalton Trans. 2013, 42, 3901. (b) Gomes, A. C.; Pillinger, M.; Nunes, P.; Gonçalves, I. S.; Abrantes, M. J. Organomet. Chem. 2014, 760, 42

(74) Salles, L.; Nixon, A. F.; Russell, N. C.; Clarke, R.; Pogorzelec, P.; Cole-Hamilton, D. J. Tetrahedron: Asymmetry 1999, 10, 1471.

(75) Jeyakumar, K.; Chand, D. Synthesis 2008, 807.

(76) Gomes, A. C.; Neves, P.; Cunha-Silva, L.; Valente, A. A.; Gonçalves, I. S.; Pillinger, M. Catal. Sci. Technol. 2016, 6, 5207.

(77) Marín, I.; Matheu, M. I.; Díaz, Y.; Castillón, S. Adv. Synth. Catal. 2010, 352, 3407.

(78) Jeyakumar, K.; Chand, D. Synthesis 2008, 1685.

(79) Goswami, S.; Maity, A. C. Tetrahedron Lett. 2008, 49, 3092.

(80) Rana, K. K.; Guin, C.; Jana, S.; Roy, S. C. Tetrahedron Lett. 2003, 44, 8597.

(81) de Noronha, R. G.; Fernandes, A. C.; Romão, C. C. Tetrahedron Lett. 2009, 50, 1407.

(82) (a) Stock, C.; Brückner, R. Synlett 2010, 2429. (b) Stock, C.; Brückner, R. Adv. Synth. Catal. 2012, 354, 2309.

(83) de Noronha, R. G.; Costa, P. J.; Romao, C. C.; Calhorda, M. J.; Fernandes, A. C. Organometallics 2009, 28, 6206.

(84) de Noronha, R. G.; Romão, C. C.; Fernandes, A. C. Catal. Commun. 2011, 12, 337.

(85) Guggilapu, S. D.; Prajapti, S. K.; Nagarsenkar, A.; Lalita, G.; Vegi, G. M. N.; Babu, B. N. New J. Chem. 2016, 40, 838.

(86) Pereira, J. G.; Sousa, S. C. A.; Fernandes, A. C. ChemistrySelect 2017, 2,4516 .

\section{Biosketches}

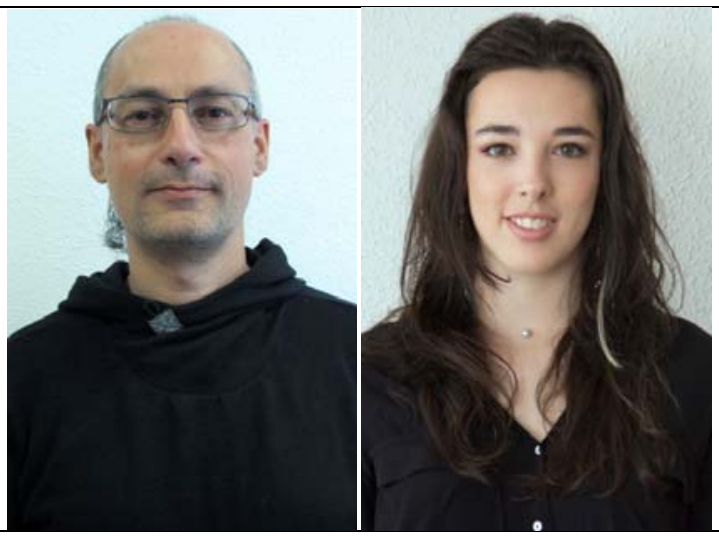

Roberto Sanz (left) was born in Burgos, Spain, in 1969. He received his Ph.D. from Universidad de Oviedo (Spain) in 1997 under the supervision of Prof. J. Barluenga and Prof. F. J. Fañanás, working on the design of new carbometalation reactions. In 1997, he took an Assistant Professor position at Universidad de Burgos, where he became Associate Professor in 2003 starting his independent career. He has been Visiting Scientist at ETH Zürich (Switzerland, 2000) with Prof. E. M. Carreira and, in 2010, he was promoted to Full Professor in Organic Chemistry. His research interests are focused on the development of new methodologies in organic synthesis in the fields of homogeneous catalysis (using gold and dioxomolybdenum complexes as well as Brønsted acids) and organolithium chemistry for the synthesis of functionalized heterocycles.

Raquel Hernández-Ruiz (right) was born and raised in Burgos, Spain. She received her B.S. degree in Chemistry from Universidad de Burgos (2013-2017) and also attended Millersville University (Pennsylvania), where she studied her senior year. Afterwards, she received her M.S. in Advanced Chemistry from University of Burgos (2017-2018). She is currently a first-year Ph.D. student under supervision of Prof. R. Sanz. Her researches focus on the use of nitroaromatics as starting materials for the Mo-catalyzed synthesis of nitrogenated polyheterocycles.

For Reviews, include photos and short biographical text for all authors. If the photo is of a group of people, specify who is shown where.

For Short Reviews, restrict the photo and biographical text to the main (starred) author(s). If the photo displays coworkers, however, they can be mentioned briefly within the main author's short biography.

Photographs (.jpg or .tif format) must be a minimum of $300 \mathrm{dpi}$ in order to reproduce well in print. 